\title{
Adipocyte-Specific Protein Tyrosine Phosphatase 1B Deletion Increases Lipogenesis, Adipocyte Cell Size and Is a Minor Regulator of Glucose Homeostasis
}

\author{
Carl Owen ${ }^{1}$, Alicja Czopek ${ }^{1}$, Abdelali Agouni ${ }^{1}$, Louise Grant ${ }^{1}$, Robert Judson ${ }^{2}$, Emma K. Lees ${ }^{1}$, George D. \\ Mcilroy ${ }^{1}$, Olga Göransson ${ }^{3}$, Andy Welch ${ }^{2}$, Kendra K. Bence ${ }^{4}$, Barbara B. Kahn ${ }^{5}$, Benjamin G. Neel ${ }^{6}$, \\ Nimesh Mody ${ }^{1}$, Mirela Delibegović ${ }^{1}{ }^{*}$
}

1 Integrative Physiology, University of Aberdeen, Aberdeen, United Kingdom, $\mathbf{2}$ School of Medical Sciences, University of Aberdeen, Aberdeen, United Kingdom, 3 Department of Experimental Medical Science, Protein Phosphorylation Unit, Lund University, Lund, Sweden, 4 Department of Animal Biology, School of Veterinary Medicine, University of Pennsylvania, Philadelphia, United States of America, 5 Division of Endocrinology, Diabetes and Metabolism, Beth Israel Deaconess Medical Centre, Boston, United States of America, 6 Campbell Family Cancer Research Institute, Ontario Cancer Institute, Princess Margaret Hospital, University of Toronto, Toronto, Canada

\begin{abstract}
Protein tyrosine phosphatase 1B (PTP1B), a key negative regulator of leptin and insulin signaling, is positively correlated with adiposity and contributes to insulin resistance. Global PTP1B deletion improves diet-induced obesity and glucose homeostasis via enhanced leptin signaling in the brain and increased insulin signaling in liver and muscle. However, the role of PTP1B in adipocytes is unclear, with studies demonstrating beneficial, detrimental or no effect(s) of adipose-PTP1Bdeficiency on body mass and insulin resistance. To definitively establish the role of adipocyte-PTP1B in body mass regulation and glucose homeostasis, adipocyte-specific-PTP1B knockout mice (adip-crePTP1B ${ }^{-1-}$ ) were generated using the adiponectin-promoter to drive Cre-recombinase expression. Chow-fed adip-crePTP1B ${ }^{-/-}$mice display enlarged adipocytes, despite having similar body weight/adiposity and glucose homeostasis compared to controls. High-fat diet (HFD)-fed adipcrePTP1B $^{-1-}$ mice display no differences in body weight/adiposity but exhibit larger adipocytes, increased circulating glucose and leptin levels, reduced leptin sensitivity and increased basal lipogenesis compared to controls. This is associated with decreased insulin receptor (IR) and Akt/PKB phosphorylation, increased lipogenic gene expression and increased hypoxia-induced factor-1-alpha (Hif-1 $\alpha$ ) expression. Adipocyte-specific PTP1B deletion does not beneficially manipulate signaling pathways regulating glucose homeostasis, lipid metabolism or adipokine secretion in adipocytes. Moreover, PTP1B does not appear to be the major negative regulator of the IR in adipocytes.
\end{abstract}

Citation: Owen C, Czopek A, Agouni A, Grant L, Judson R, et al. (2012) Adipocyte-Specific Protein Tyrosine Phosphatase 1B Deletion Increases Lipogenesis, Adipocyte Cell Size and Is a Minor Regulator of Glucose Homeostasis. PLoS ONE 7(2): e32700. doi:10.1371/journal.pone.0032700

Editor: Maria Eugenia Saez, Neocodex, Spain

Received September 6, 2011; Accepted January 30, 2012; Published February 28, 2012

Copyright: (C) 2012 Owen et al. This is an open-access article distributed under the terms of the Creative Commons Attribution License, which permits unrestricted use, distribution, and reproduction in any medium, provided the original author and source are credited.

Funding: This work was supported by the British Heart Foundation project grant awarded to MD (PG/09/048/27675 and PG/11/8/28703) and the Diabetes UK project grant awarded to MD. (BDA/RD08/0003597). This work was also supported by a STINT grant awarded to OG; Institutional Grant for Young Researchers, from The Swedish Foundation for International Cooperation in Research and Higher Education. CO is the recipient of a BBSRC postgraduate studentship; NM is the recipient of a British Heart Foundation intermediate basic research fellowship. The funders had no role in study design, data collection and analysis, decision to publish, or preparation of the manuscript.

Competing Interests: The authors have declared that no competing interests exist.

*E-mail: m.delibegovic@abdn.ac.uk

\section{Introduction}

Caloric excess and a sedentary lifestyle are major contributors to epidemic obesity levels in Western society. Obesity is associated with complex disorders, including cardiovascular disease and type 2 diabetes [1]. This rising burden of metabolic disease requires the development of new therapeutic strategies.

White adipose tissue (WAT) is the main site for storage of excess energy from food intake, and plays a key role in sensing and coordinating adaptations in whole body glucose metabolism [2,3]. White adipose tissues function as endocrine and paracrine organs by secreting various adipokines. These bioactive molecules, including leptin, adiponectin, visfatin, omentin, tumor necrosis factor- $\alpha(\mathrm{TNF}-\alpha)$, resistin, retinol-binding protein 4 (RBP4) and many others influence metabolic processes such as food intake, glucose- and lipid-metabolism, inflammation and insulin resistance
[4]. Insulin resistance precedes the development of type 2 diabetes, and is characterized by reduced insulin-dependent glucose uptake into muscle, adipose tissue and other insulin-sensitive peripheral tissues, inadequate suppression of hepatic glucose production, and accumulation of hepatic lipids [5].

The mechanism(s) leading to insulin resistance remain unclear $[6,7]$; however, it is generally agreed that impaired post-insulin receptor (IR) signal transduction is involved [8]. Insulin is secreted from pancreatic $\beta$-cells in response to nutrients and transported to target tissues via the circulatory system. Insulin signaling is activated when insulin binds to the IR, located on the plasma membrane. The IR is a heterodimeric complex containing two $\alpha$-subunits, which enable insulin binding, and two $\beta$-subunits, which have inherent tyrosine kinase activity. Once the $\alpha$-subunits are bound by ligands, the $\beta$-subunits can transphosphorylate, which enhances their kinase activity [9]. The 
activated IR phosphorylates substrates including the insulin receptor substrate (IRS) proteins 1-4, Shc, Cbl and Gab-1 [10]. Upon phosphorylation, the IRS proteins act as docking sites for several src homology region 2 (SH2) domain containing proteins, including the p85 regulatory subunit of phosphatidylinositol 3kinase (PI3K), which results in PI3K activation [11]. PI3K activation subsequently leads to activation of protein kinase $\mathrm{B}$ (Akt/PKB), which has diverse intracellular targets, including glycogen synthase kinase 3 (GSK-3) and the mammalian target of rapamycin (mTOR). Importantly, $\mathrm{Akt} / \mathrm{PKB}$ is required to promote translocation of GLUT4 to the plasma membrane, and consequently, increase glucose uptake [12].

Protein-tyrosine phosphatase 1B (PTP1B) is a ubiquitously expressed non-receptor tyrosine phosphatase and a key negative regulator of leptin and insulin signaling [13]. PTP1B has a catalytic (PTP) domain, followed by a regulatory region and a membrane localization domain, which tethers the enzyme to the cytoplasmic face of the endoplasmic reticulum (ER) $[14,15]$. Global PTP1B ${ }^{-/-}$mice exhibit reduced adiposity, enhanced tyrosine phosphorylation of the IR in muscle and liver - but not adipose tissue - and display improved glucose homeostasis as a consequence of increased systemic insulin sensitivity [16,17]. The increased insulin sensitivity in $\mathrm{PTP}_{1} \mathrm{~B}^{-/-}$mice is tissue-specific, as glucose uptake is elevated in muscle, but not in adipose tissue [16]. PTP1B tissue-specific knockout mice with deletions in brain, liver or skeletal muscle were generated to investigate the site $(\mathrm{s})$ and mechanism(s) of PTP1B action in the regulation of insulin sensitivity and body mass/adiposity $[5,18,19]$. Neuronal-specific PTP1B knockout mice, despite increased leptin levels, exhibit reduced body mass and adiposity due to leptin hypersensitivity, resulting in reduced food intake and increased energy expenditure [18]. Furthermore, mice lacking PTP1B specifically in proopiomelanocortin (POMC) neurons display reduced adiposity, improved leptin sensitivity, increased energy expenditure and improved glucose homeostasis on a high-fat diet (HFD) compared with wild-type mice [20]. Muscle- or liver-specific PTP1B knockouts have comparable body weight and adiposity to controls. However, they exhibit improved insulin sensitivity and glucose tolerance $[5,19]$. Mice with an adipose-deficiency of PTP1B were also generated by using the adipocyte protein 2 (aP2)-promoter cassette to drive Cre recombinase expression. These aP2-

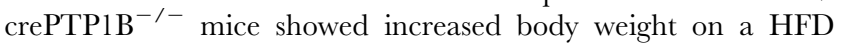
compared with littermate controls [18]. However, whether adipocyte-PTP1B was the sole cause of the observed weight gain in these mice is unclear, as the $\mathrm{aP} 2$ promoter is known to delete in cell types other than adipocytes [21,22].

Although the negative regulatory effects of PTP1B activity on insulin action have been well documented in the muscle and liver, studies on the role of PTP1B in adipocytes have provided ambiguous results. Insulin-stimulated IR phosphorylation is unchanged in the adipose tissue of $\mathrm{PTP}^{-} \mathrm{B}^{-}$mice [17]. However, over-expression of PTP1B in 3T3-L1 adipocytes inhibits insulin-stimulated phosphorylation of the IR and IRS-1, and decreases PI3K activation [23,23,24]. Ruffolo et al. [25] demonstrated increased basal (ad libitum fed/non-insulin stimulated) phosphorylation of p70S6K at site Thr-389 in isolated adipocytes from global $\mathrm{PTP} \mathrm{B}^{-/-}$mice, compared with controls. They suggested that the enhanced basal phosphorylation of p70S6K, which decreased IRS-1 levels, was the cause of reduced glucose uptake into isolated adipocytes from $\mathrm{PTP}_{1} \mathrm{~B}^{-/-}$mice and that adipose-PTP1B deletion causes tissue-specific insulin resistance. By contrast, antisense oligonucleotides, which lower PTP1B levels only in adipose tissue and liver, reduce diet-induced obesity and improve insulin signaling in obese $(o b / o b)$ and diabetic $(d b / d b)$ mice
[26,27]. It is not clear whether these effects reflected loss of PTP1B in adipose tissue or liver (or both). Here we used mice expressing Cre recombinase under the control of an adiponectin-promoter cassette [28] - which is exclusively expressed in adipocytes [29] to delete PTP1B, and thereby definitively establish the physiological and molecular consequences of adipocyte-specific PTP1B deletion in vivo.

\section{Materials and Methods}

\section{Ethics statement}

All animal procedures were approved by the University of Aberdeen Ethics Review Committee Board and performed under a project license approved by the Home Office under the Animals (Scientific Procedures) Act 1986 (PPL60/3951).

\section{Animal studies}

$\mathrm{PTP}_{1} \mathrm{~B}^{\mathrm{fl} / \mathrm{fl}}$ mice [18] and mice expressing Cre recombinase (Cre) under the control of the adiponectin promoter [28] were described previously; the latter were generously provided by Dr Evan Rosen, Beth Israel Deaconess Medical Centre, Harvard Medical School, Boston, USA. To generate adipocyte-specific $\mathrm{PTP}_{1 \mathrm{~B}}{ }^{-/-}$mice, $\mathrm{PTP} 1 \mathrm{~B}^{\mathrm{fl} / \mathrm{fl}}$ mice were crossed with adiponectincre mice. DNA extraction and genotyping for the PTP1B floxed allele and the presence of Cre by PCR were performed as described previously [18]. Sequences of primers used for PCR are provided in the appendix (Table S1). Mice studied were agematched littermates, which had been backcrossed to pure C57BL/ 6 mice for seven generations. For most studies, mice were housed in groups and maintained at $22-24^{\circ} \mathrm{C}$ on a 12 -h light/dark cycle with free access to food and water. To measure food intake, mice were caged individually and the weight of food consumed was measured over a four-week period. For insulin signaling experiments, 25-week old chow- or HFD-fed mice were fasted overnight and then injected intraperitoneally with saline or insulin (10 mU/g body weight). After 10 minutes, mice were sacrificed by cervical dislocation. Tissues were dissected immediately and frozen in liquid nitrogen.

\section{Body composition}

At weaning (21 days), mice were placed on standard 3.4\% fat chow pellet diet (Rat and Mouse Breeder and Grower, Special Diets Services, DBM, Scotland) or HFD (Adjusted Calories Diet, $55 \%$ fat, Harlan Teklad, USA) and weight was recorded weekly. The approximate fatty acid profile of Adjusted Calories Diet $(\%$ total fat) was $28 \%$ saturated, $30 \%$ trans, $28 \%$ monounsaturated (cis) and $14 \%$ polyunsaturated (cis), as described previously [30]. Adiposity was measured at the end of the study by individually weighing dissected fat pads.

\section{Isolation of peritoneal macrophages}

Mice were sacrificed by cervical dislocation. DMEM (Gibco, Paisley, UK) was injected intraperitoneally, mice were agitated, and medium containing macrophages was collected. Peritoneal macrophages were maintained for 24-48 hours at $37^{\circ} \mathrm{C}$ in a humidified atmosphere with $5 \% \mathrm{CO}_{2}$.

\section{Isolation and maturation of bone marrow derived macrophages}

Mice were sacrificed by cervical dislocation. Bone marrow derived macrophages were obtained by flushing out femurs and tibiae with DMEM (Gibco). Cells were passed through $19 \mathrm{G}$ needles to disrupt the bone marrow plugs and centrifuged at $900 \mathrm{~g}$ 
for $5 \mathrm{~min}$. Bone marrow mononuclear phagocyte precursor cells were matured for seven days in culture medium (DMEM (Gibco), 10\% FBS (Invitrogen, Paisley, UK), $100 \mathrm{U} / \mathrm{ml}$ penicillin (Gibco) and $100 \mathrm{mg} / \mathrm{ml}$ streptomycin (Gibco)) supplemented with $20 \%$ L929-cell conditioned medium in untreated polystyrene Petri dishes. Bone marrow derived macrophages (BMDM) were maintained at $37^{\circ} \mathrm{C}$ in a humidified atmosphere with $5 \% \mathrm{CO}_{2}$.

\section{Histology}

Epididymal, subcutaneous and peri-renal adipose tissue was fixed in formaldehyde, embedded in paraffin, sectioned, and stained with hematoxylin and eosin. Average adipocyte diameter was quantified by measuring 50 adipocytes at $20 \times$ magnification, as described previously [31]. Scale bars were determined by measurement with a scale calibrator (Stage Micrometer, Graticules Ltd, Kent, England).

\section{Metabolic measurements}

Tail blood glucose from fasted (5-h or 16-h) mice was measured by using glucometers (Accu-Chek, Burgess Hill, UK). Serum insulin, leptin (CrystalChem, Downers Grove, USA), adiponectin (Millipore) and TNF- $\alpha$ levels (R\&D Systems, Minneapolis, USA) were determined by ELISA. Serum RBP4 was determined by immunoblotting. Glucose and insulin concentrations were used to calculate the homeostasis model assessment of insulin resistance (HOMA-IR), a reliable marker of insulin sensitivity [32], which is defined as: fasting glucose $(\mathrm{mg} / \mathrm{dl}) \times$ fasting insulin $(\mu \mathrm{U} / \mathrm{ml}) / 405$. Serum glucose and triglycerides were determined using appropriate kits (Sigma, Gillingham, UK). Glucose tolerance tests (GTT) were performed as described previously [16,33]. Insulin tolerance tests (ITT) were performed on fasted (5-h) mice by measuring blood glucose values immediately before and at 15, 30, 60, and $120 \mathrm{~min}$ after intraperitoneal injection of insulin (chow $0.6 \mathrm{mU} / \mathrm{g}$ body weight and HFD $1.1 \mathrm{mU} / \mathrm{g}$ body weight; Humulin R, Eli Lilly Corp., Indianapolis, USA).

\section{Leptin sensitivity}

Mice were caged individually with free access to food and water. Food intake and body weight were monitored daily throughout the study. Mouse leptin (R\&D Systems) was administered to chowand HFD-fed adip-crePTP1B ${ }^{-/-}$and control littermates intraperitoneally twice daily for three days (morning and evening dose, $0.5 \mu \mathrm{g} / \mathrm{g}$; total dose for 24-h period, $1.0 \mu \mathrm{g} / \mathrm{g}$ ).

\section{Positron emission tomography (PET) scanning}

PET scanning was carried out using the glucose analog, 2deoxy-2- $\left({ }^{18} \mathrm{~F}\right)$ fluoro-D-glucose (FDG), a marker of glucose metabolism, which was manufactured in the radiochemistry facility at the University of Aberdeen. FDG administration was performed in conscious, fasted (8-h) mice which had free access to water. Mice were kept at $35^{\circ} \mathrm{C}$ by placing cages on a heating pad. Warming started at least $30 \mathrm{~min}$ before FDG injection and continued during the FDG uptake period. Mice were conscious during the FDG uptake with cages kept in the dark. In the pre-imaging period, FDG (range: 17.8-22.1 MBq) was intraperitoneally injected (injected volume $0.5 \mathrm{ml}$ ). The uptake occurred outside the scanner (in the cage) for $45 \mathrm{~min}$, during which time the mice were placed on a running wheel. Running was voluntary and the time that each mouse exercised was recorded. Mice were anesthetized with isofluorane $\left(1.5-2.0 \%\right.$ with $\left.2 \mathrm{l} / \mathrm{min} \mathrm{O}_{2}\right)$, and were placed on the bed of the scanner in the supine position (head first). The body and the head of the mouse were secured to the bed with tape. A CT scan was obtained first, followed by a $40 \mathrm{~min}$ PET. Emission data was collected using a SEDECAL Argus dual-ring PET scanner (Madrid, Spain), in a temperature-controlled room. A complete performance evaluation of the SEDECAL Argus dual-ring PET scanner has been performed, as described previously [34]. Corrections for attenuation, random coincidence and photon scatter were applied and the images were reconstructed using Fourier Rebinning and a 2D ordered subsets expectation maximization algorithm, supplied by the manufacturer. The images were converted into semi-quantitative units (SUVs) by dividing the uptake by the injected activity and multiplying by the weight of mice. Analysis was performed by drawing regions of interest on the registered PET and CT images and calculating the ratio of activity in the brain, muscle and brown adipose tissue. For each tissue, the region of interest (ROI) was defined in a single mouse and copied to the scans from the other mice.

\section{Adipocyte isolation}

All chemicals were from Fisher Scientific (Loughborough, UK) (unless stated otherwise). Mice were sacrificed by cervical dislocation. Fresh epididymal adipose tissue was digested at $37^{\circ} \mathrm{C}$ in a shaking water bath $(100 \mathrm{rpm})$ for 60 minutes in Krebs-Ringer-Hepes (KRH) buffer $\mathrm{pH} 7.4$ which contained $125 \mathrm{mM} \mathrm{NaCl}, 5 \mathrm{mM} \mathrm{KCl}, 1 \mathrm{mM} \mathrm{KH_{2 }} \mathrm{PO}_{4}, 2.5 \mathrm{mM} \mathrm{MgSO} 4$, $2.5 \mathrm{mM} \mathrm{CaCl}_{2} 2 \mathrm{H}_{2} \mathrm{O}, 2 \mathrm{mM}$ glucose, $25 \mathrm{mM}$ HEPES, 3.5\% BSA (Cohn Fraction V), $200 \mathrm{nM}$ adenosine (Sigma) and $1 \mathrm{mg} / \mathrm{ml}$ type I collagenase $(244 \mathrm{U} / \mathrm{mg}$ ) (Worthington Biochemical, Lakewood, USA). The digest was filtered through cotton mesh to remove debris and washed three times in KRH buffer without collagenase. At the final wash, $2 \mathrm{ml}$ of dinonyl phthalate oil (Sigma) was added to the adipocytes, which were then centrifuged for $5 \mathrm{~min}$ at $800 \mathrm{rpm}$. The top layer of adipocytes were transferred to microcentrifuge tubes and centrifuged for $1 \mathrm{~min}$ at $3000 \mathrm{rpm}$. The infranatant was removed with $19 \mathrm{G} \times 1 \quad 1 / 2$ syringes. Adipocyte lysates were then prepared in radioimmunoprecipitation assay (RIPA) buffer containing fresh sodium orthovanadate and protease inhibitors, as described previously [19].

\section{Lipogenesis assay}

The assay was performed as described previously [35]. Adipocytes were digested in KRH buffer $\mathrm{pH} 7.4$ and filtered, as described above, but washed three times and resuspended in a low glucose variant of $\mathrm{KRH}$ buffer containing $0.55 \mathrm{mM}$ glucose. The adipocytes were resuspended at a $2 \%$ packed cell volume, which was determined as described previously [36]. The assay was performed in quadruplicate. $700 \mu \mathrm{l}$ of the $2 \%$ adipocyte cell suspension was added to each tube and incubated for 1 -h at $37^{\circ} \mathrm{C}$ with $14 \mu \mathrm{l}$ of $22 \mu \mathrm{Ci} / \mathrm{ml}$ tritiated glucose (D-[6$3 \mathrm{H}]$-glucose, Perkin Elmer, Cambridge, UK) and 0, 1, 3, 10, 30 and $100 \mathrm{nM}$ insulin concentrations. After the incubation, the assay was stopped by adding $3.5 \mathrm{ml}$ of 2,5-diphenyloxazole (Sigma) and 1,4-bis(5-phenloxazol-2-yl)benzene (Sigma) toluenebased scintillation liquid (Sigma). A zero sample was also included in the experiment to measure how much glucose ends up in the lipid phase during extraction without having been used for lipid synthesis. This was done by adding $700 \mu$ of the $2 \%$ adipocyte cell suspension to scintillation tubes containing $14 \mu \mathrm{l}$ of $22 \mu \mathrm{Ci} / \mathrm{ml}$ tritiated glucose which was then stopped immediately by adding $3.5 \mathrm{ml}$ PPO-POPOP toluene-based scintillation liquid.

\section{Immunoblotting}

Tissue lysates were prepared in RIPA buffer containing fresh sodium orthovanadate and protease inhibitors, as described previously [19]. Proteins were separated by $3-8 \%, 10 \%$ or 
4-12\% SDS-PAGE and transferred to nitrocellulose membranes. Immunoblots were performed using antibodies from Cell Signaling (Cell Signaling by NEB, Hitchin, UK) (unless stated otherwise) against pIR Y1158, pIRS-1 S636/639, total IRS-1, pAkt/PKB S473, total Akt/PKB, pERK1/2 MAPK T202/Y204, pS6 ribosomal protein S235/236, pS6 ribosomal protein S240/244, p-p70S6K T389, total p70S6K, p-mTOR S2448, total mTOR (Santa Cruz, Insight Biotechnology, Wembley, UK) pGSK-3 $\alpha$ S21, pGSK-3 $\beta$ S9, pAMPK T172, total AMPK $\alpha$, pIR Y1162/63 (Invitrogen), total IR (Santa Cruz), SHP2 (Santa Cruz), pIRS-1 Y608 (CalBiochem), RBP4 (Dako, Cambridgeshire, UK), TCPTP (R\&D Systems) and PTP1B (Millipore, Chandlers Ford, UK). Immunoblots were developed with horseradish peroxidase-conjugated secondary antibodies, visualized using enhanced chemiluminescence, and quantified by densitometry scanning with Image J or BiolD software (PeqLab, Fareham, UK).

\section{Immunoprecipitations}

Tissue lysates were prepared in RIPA buffer containing fresh sodium orthovanadate and protease inhibitors as described previously [19]. IR was immunoprecipitated by adding $1 \mu \mathrm{g}$ of IR antibody (Santa Cruz) to each $200 \mu \mathrm{g}$ sample of epididymal adipose tissue lysate, and then incubated overnight in an Eppendorf Thermomixer (Eppendorf UK Ltd, Cambridge, UK) at $4{ }^{\circ} \mathrm{C}$ with constant shaking at $550 \mathrm{rpm}$. Protein-A Sepharose beads were washed 4 times in buffer containing $50 \mathrm{mM}$ Tris/HCl pH 7.5 and $150 \mathrm{mM} \mathrm{NaCl}$ before being resuspended in RIPA at 1:1 (beads/buffer, v/v). Thirty (30) $\mu \mathrm{l}$ of bead slurries were added to each immunoprecipitation sample, which was then incubated with gentle end-over-end mixing for 2 -h at $4^{\circ} \mathrm{C}$. Proteins from the immunoprecipitates were resolved by $10 \%$ SDS-PAGE, transferred to nitrocellulose membranes, and immunoblots were performed as described above, using mouse anti-phospho tyrosine antibodies (Cell Signaling).

\section{Ex vivo insulin signaling}

Adipocytes were digested in KRH buffer $\mathrm{pH} 7.4$ and filtered, as described above, and then resuspended in a $10 \%$ cells/KRH buffer suspension. The $10 \%$ adipocyte suspensions were aliquoted into $1.5 \mathrm{ml}$ tubes containing a final concentration of $0 \mathrm{nM}$, $1 \mathrm{nM}, 10 \mathrm{nM}$ or $100 \mathrm{nM}$ insulin. Adipocytes were incubated in a water bath for 10 minutes at $37^{\circ} \mathrm{C}$ with gentle shaking. Infranatant was removed from adipocyte cell suspensions and the remaining adipocytes were lysed in RIPA buffer containing fresh sodium orthovanadate and protease inhibitors, as described previously [19].

\section{Gene expression analysis}

Total RNA was isolated from mouse epididymal adipose tissue using TRI Reagent (Ambion, Warrington UK), according to the manufacturer's protocol. First strand cDNA was synthesized from $1 \mu \mathrm{g}$ of total RNA employing the Bioline Bioscript ${ }^{\mathrm{TM}}$ Preamplification System and oligo(dT) $)_{12-18}$. Four (4) $\mu \mathrm{l}$ of diluted cDNA (1:100) was used to amplify target genes by real-time RTPCR $(20 \mu \mathrm{l})$, using GoTaq qPCR Master Mix (Promega, Southampton, UK). The Roche LightCycler ${ }^{\circledR} 480$ System (Roche Diagnostics, Burgess Hill, UK) was used for analysis. Relative gene expression was calculated using the comparative $\mathrm{Ct}(2-\Delta \Delta \mathrm{Ct})$ method. The relative copy numbers of mouse hypoxanthineguanine phosphoribosyltransferase $(H p r t)$ mRNA was used for normalization. PGRs were followed by melting curves $\left(60-95^{\circ} \mathrm{C}\right)$. Sequences of primers used real-time quantitative PCR are provided in the appendix (Table $\mathrm{S} 1$ ).

\section{Data analysis}

Data are expressed as mean \pm SEM. Statistical analyses were performed using one-way ANOVA with Tukey's multiple comparison post tests, two-way ANOVA with Bonferroni multiple comparisons post tests, and two-tailed Student's t tests, as appropriate. $P \leq 0.05$ was considered statistically significant. GraphPad Prism 5 and SPSS Version 17 statistical software were used for analyses.

\section{Results}

Adipocyte-specific deletion of PTP1B increases adipocyte cell size but does not affect body mass, adiposity or food intake

Mice with an adipocyte-specific deletion of PTP1B (hereafter termed adip-crePTP1B ${ }^{-/-}$mice) were generated by crossing $\mathrm{PTP} 1 \mathrm{~B}^{\mathrm{fl} / \mathrm{fl}}$ mice (hereafter termed $\mathrm{fl} / \mathrm{fl}$ mice) to transgenic mice with a knock-in of Cre into the adiponectin locus [28]. To account for potential effects of adiponectin gene dosage or Cre expression, mice heterozygous for adipocyte-specific PTP1B deletion and adiponectin-cre-alone mice (hereafter termed adip$\mathrm{crePTP}_{1 \mathrm{~B}}{ }^{+/-}$and adip-cre mice, respectively) were included in the study. Adip-crePTP1B ${ }^{-/-}$mice lack PTP1B in brown adipose tissue (BAT), WAT and isolated white adipocytes but not in other tissues (Figure 1A). WAT from adip-crePTP1B ${ }^{+/-}$ mice also had decreased PTP1B levels $(\sim 50 \%)$ as expected from a heterozygous deletion (Figure S1). PTP1B levels were normal in $\mathrm{fl} / \mathrm{fl}$ and adip-cre mice (Figure $1 \mathrm{~A}$ and Figure $\mathrm{Sl}$ ). Importantly, there was no deletion of macrophage-PTP1B in adip-crePTP1B $\mathrm{B}^{-/-}$mice (Figure $1 \mathrm{~A}$ ), which is a potential concern in studies that use aP2-cre mice to achieve deletion in adipocytes [21]. All groups of mice were placed onto either chow $(3.4 \%$ fat $)$ or HFD $(55 \%$ fat $)$ after weaning. Adip-

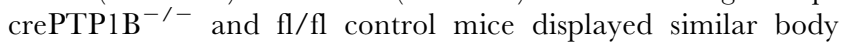
weights (Figure 1B) and lengths (data not shown) on chow diet. All groups of mice gained more weight on HFD than on chow, but body weights (Figures 1 B and $\mathrm{C}$ ) and lengths (data not shown) were comparable between genotypes. Adiposity (Figure 1D) and food intake (Figure 1E) were also similar in all groups of mice on chow and HFD. Interestingly, hematoxylin and eosin staining of epididymal adipose tissue sections revealed significant increases in adipocyte cell size in chow- and HFD-fed adip-crePTP1B ${ }^{-1-}$ mice compared with their respective controls (Figures 1F, G and H). The increased adipocyte cell size appears to be depot specific as there were no cell size differences in subcutaneous or peri-renal fat pads between HFD-fed adip-crePTP1B ${ }^{-/-}$and fl/fl control mice (Figure S4). The increased size also appears to be dose specific as adip-

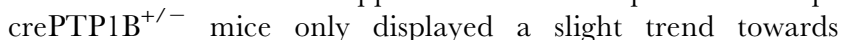
enlarged adipocytes on a HFD (Figure $1 \mathrm{G}$ and $\mathrm{H}$ ).

\section{Mild glucose intolerance/insulin resistance in HFD-fed adip-crePTP1B ${ }^{-/-}$mice}

Compared to $\mathrm{fl} / \mathrm{fl}$ controls, adip-crePTP1B ${ }^{-/-}$mice displayed significantly higher fasted glucose levels at 8 and 14 weeks HFD, with no differences in fasted serum insulin (Table 1). The homeostasis model assessment of insulin resistance (HOMA-IR) was significantly higher in adip-crePTP1B ${ }^{-/-}$mice compared with $\mathrm{fl} / \mathrm{fl}$ controls after 14 weeks of HFD (Table 1). Glucose (GTT) and insulin (ITT) tolerance tests were performed on chow- and HFD-fed adip-crePTP1B ${ }^{-/-}$mice to assess whole body glucose homeostasis. There were no significant differences 

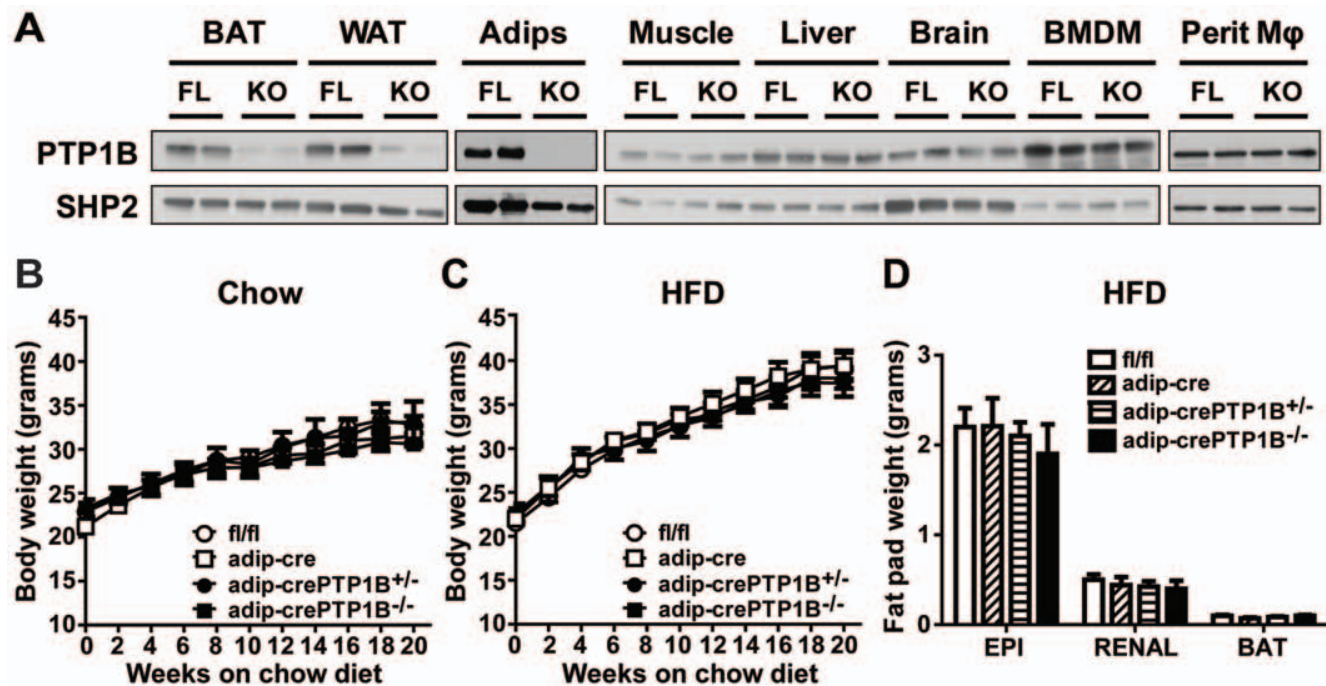

$\mathbf{E}$

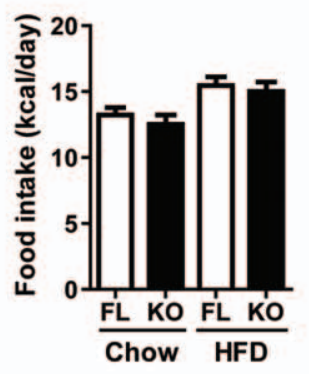

$\mathbf{F}$

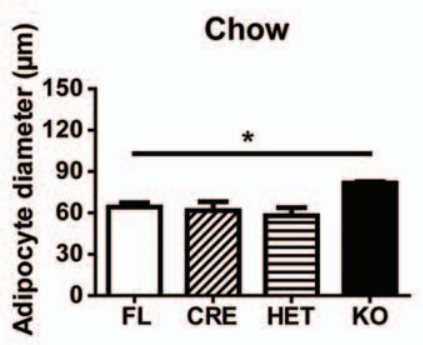

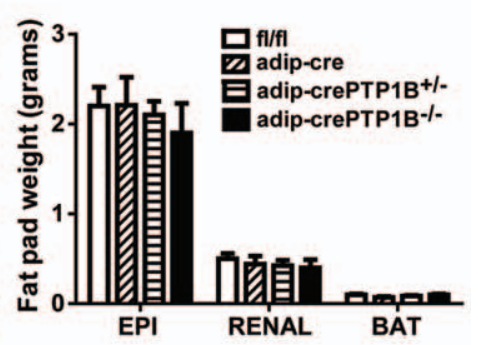

G

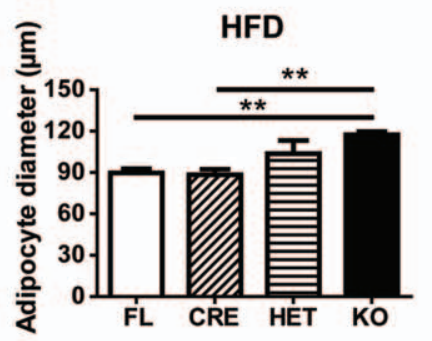

H

Chow
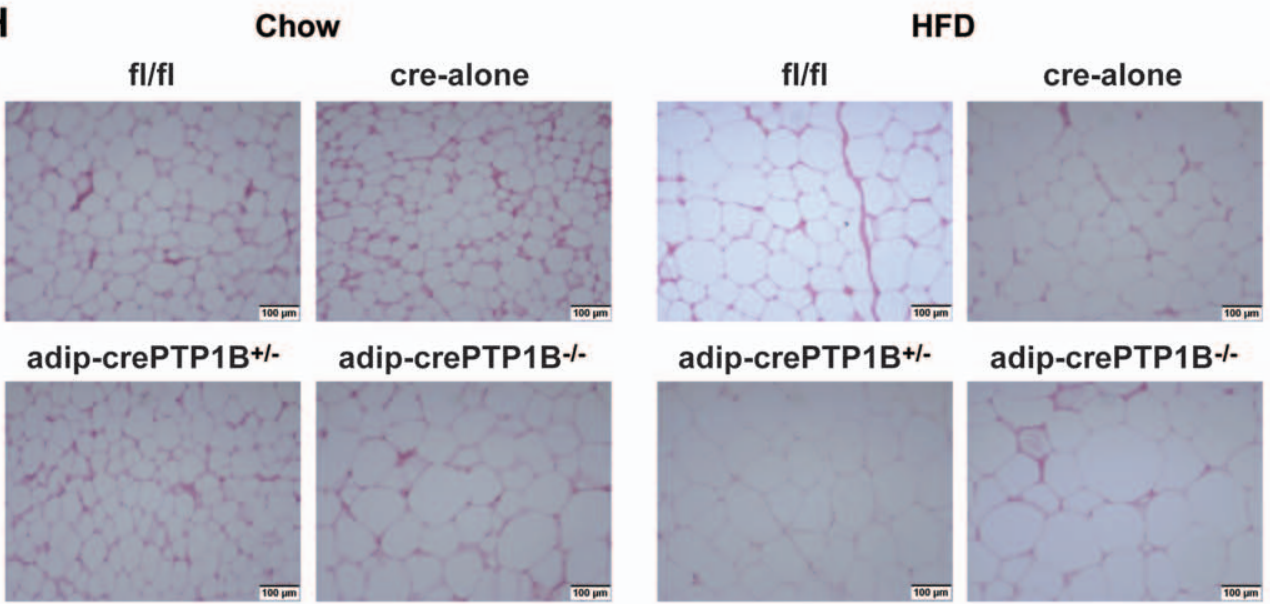

Figure 1. Adipocyte-specific deletion of PTP1B has no effect on body mass, adiposity or food intake. A: Deletion efficiency of PTP1B in $\mathrm{fl} / \mathrm{fl}$ controls (FL) and adip-crePTP1B ${ }^{-1-}$ mice (KO), as detected by immunoblotting. Tissues shown, (left to right) are brown adipose tissue (BAT), white adipose tissue (WAT), isolated adipocytes (Adips), muscle, liver, brain, bone marrow derived macrophages (BMDM) and intraperitoneal macrophages (Perit M $\varphi$ ). B: Weight curves for fl/fl $(n=14)$, adip-cre $(n=6)$, adip-crePTP1B ${ }^{+-}(n=5)$ and adip-crePTP1B ${ }^{-1-}$ mice $(n=4)$ on chow diet for 21 weeks from weaning. C: Weight curves for fl/fl $(n=13)$, adip-cre $(n=6)$, adip-crePTP1B ${ }^{+/-}(n=5)$ and adip-crePTP1B ${ }^{-1-}$ mice $(n=4)$ on HFD diet for 21 weeks. $D$ : Fat pad weight of mice on HFD for 21 weeks. Tissues shown, (left to right) are epididymal (EPI), peri-renal (RENAL) and brown adipose tissue (BAT). $\mathrm{Fl} / \mathrm{fl}(n=13)$; adip-cre $(n=6)$; adip-crePTP1B ${ }^{+-}(n=5)$; adip-crePTP1B ${ }^{-1-}(n=4)$. E: Daily food intake of mice on chow or HFD. fl/fl (FL) (chow $n=5, \mathrm{HFD}$ $n=7)$; adip-crePTP1B ${ }^{-\prime-}(\mathrm{KO})$ (chow $\left.n=4, \mathrm{HFD} n=5\right)$. F: Increased epididymal adipocyte cell size in chow-fed adip-crePTP1B ${ }^{-1-}$ mice $(\mathrm{KO})$ compared with adip-crePTP1B ${ }^{+/-}$mice (HET), fl/fl (FL) and cre-alone controls (CRE). G: Increased epididymal adipocyte cell size in HFD-fed adip-crePTP1B ${ }^{-\prime-}$ mice (KO) compared with adip-crePTP1B ${ }^{+-}$mice (HET), fl/fl and cre-alone controls (FL/CRE). $H$ : Hematoxylin and eosin stained epididymal white adipose tissue of mice on chow or HFD diet for 21 weeks. $n=4$ mice/group. White circles $=\mathrm{fl} / \mathrm{fl}$; white squares $=$ adip-cre; black circles $=$ adip-

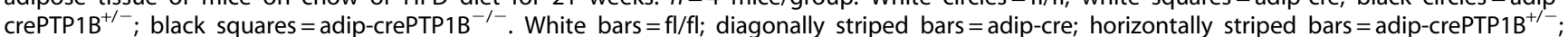
black bars $=$ adip-crePTP1B ${ }^{-1-}$. Data are represented as mean \pm SEM. Data were analyzed using two-tailed Student's $t$ test ( $\left.{ }^{* *} P<0.01\right)$. doi:10.1371/journal.pone.0032700.g001 
Table 1. Metabolic parameters in fasted fl/fl, adip-cre, adip-crePTP1B ${ }^{+/-}$and adip-crePTP1B ${ }^{-/-}$mice.

\begin{tabular}{|c|c|c|c|c|}
\hline Parameter & $\mathbf{f l} / \mathbf{f l}$ & adip-cre & $\begin{array}{l}\text { adip-cre } \\
\text { PTP1B }^{+/-}\end{array}$ & $\begin{array}{l}\text { adip-cre } \\
\text { PTP1B }^{-\prime-}\end{array}$ \\
\hline \multicolumn{5}{|c|}{ Blood Glucose (mg/dl) } \\
\hline Chow 14 Weeks & $63.5 \pm 7.9$ & $51.2 \pm 7.7$ & $71.8 \pm 7.1$ & $63.6 \pm 7.3$ \\
\hline HFD 8 Weeks & $99.9 \pm 6.1$ & $115.8 \pm 8.8$ & $114.6 \pm 5.6$ & $148.4 \pm 21.9 *$ \\
\hline HFD 14 Weeks & $64.7 \pm 8.9$ & $96.5 \pm 11.9$ & $90.7 \pm 19.3$ & $118.4 \pm 13.1 *$ \\
\hline \multicolumn{5}{|c|}{ Serum Insulin (ng/ml) } \\
\hline Chow 14 Weeks & $0.1 \pm 0.02$ & $0.17 \pm 0.03$ & $0.16 \pm 0.03$ & $0.08 \pm 0.02$ \\
\hline HFD 8 Weeks & $1.56 \pm 0.22$ & $2.1 \pm 0.31$ & $1.56 \pm 0.05$ & $1.29 \pm 0.37$ \\
\hline HFD 14 Weeks & $2.42 \pm 0.5$ & $2.9 \pm 0.51$ & $2.34 \pm 0.28$ & $3.23 \pm 1.02$ \\
\hline \multicolumn{5}{|l|}{ HOMA-IR ${ }^{a}$} \\
\hline Chow 14 Weeks & $0.37 \pm 0.08$ & $0.44 \pm 0.07$ & $0.62 \pm 0.14$ & $0.24 \pm 0.06$ \\
\hline HFD 8 Weeks & $8.3 \pm 1.1$ & $12.93 \pm 2.15$ & $10.11 \pm 0.9$ & $11.29 \pm 0.53$ \\
\hline HFD 14 Weeks & $7.87 \pm 1.57$ & $15.14 \pm 3.61$ & $11.87 \pm 3.44$ & $19.51 \pm 5.38 *$ \\
\hline \multicolumn{5}{|c|}{ Serum Leptin (ng/ml) } \\
\hline Chow 14 Weeks & $0.93 \pm 0.16$ & $1.46 \pm 0.58$ & $1.27 \pm 0.53$ & $1.95 \pm 0.55 \dagger$ \\
\hline HFD 8 Weeks & $0.68 \pm 0.18$ & $1.85 \pm 0.58$ & $1.52 \pm 0.31$ & $4.60 \pm 1.16 *$ \\
\hline HFD 14 Weeks & $2.61 \pm 1.05$ & $6.46 \pm 1.59$ & $4.82 \pm 0.51$ & $6.81 \pm 2.21$ \\
\hline \multicolumn{5}{|c|}{ Serum Adiponectin ( $\mu \mathrm{g} / \mathrm{ml})$} \\
\hline Chow 21 Weeks & $15.67 \pm 2.11$ & $11.92 \pm 0.99$ & $15.10 \pm 1.73$ & $16.84 \pm 1.55$ \\
\hline HFD 21 Weeks & $15.50 \pm 1.86$ & $13.99 \pm 1.26$ & $16.95 \pm 1.46$ & $15.53 \pm 1.13$ \\
\hline \multicolumn{5}{|l|}{ Serum RBP4 (AU) } \\
\hline Chow 21 Weeks & $1.0 \pm 0.03$ & ND & ND & $1.02 \pm 0.05$ \\
\hline HFD 21 Weeks & $0.94 \pm 0.07$ & ND & ND & $0.82 \pm 0.07$ \\
\hline \multicolumn{5}{|c|}{ Serum Triglycerides (mg/dl) } \\
\hline Chow 21 Weeks & $82.2 \pm 9.1$ & $78.4 \pm 12.0$ & $91.6 \pm 22.6$ & $95.0 \pm 22.4$ \\
\hline HFD 21 Weeks & $128.6 \pm 13.2$ & $106.6 \pm 19.4$ & $123.9 \pm 20.4$ & $97.9 \pm 14.2$ \\
\hline \multicolumn{5}{|c|}{ Serum Free Fatty Acids (mM) } \\
\hline Chow 21 Weeks & $1.34 \pm 0.1$ & $1.13 \pm 0.14$ & $0.96 \pm 0.25$ & $0.8 \pm 0.18$ \\
\hline HFD 8 Weeks & $1.82 \pm 0.18$ & $1.37 \pm 0.15$ & $1.96 \pm 0.21$ & $1.45 \pm 0.17$ \\
\hline
\end{tabular}

${ }^{a}$ HOMA-IR, homeostasis model assessment of insulin resistance. Data are means \pm SEM and were analyzed by one-way ANOVA with Tukey's multiple comparison post tests or two-tailed student's t test.

${ }^{*} P<0.05$;

$\dagger=0.09$ for the indicated genotype compared with PTP1B fl/fl control littermates. $n=4-14$ mice/group.

doi:10.1371/journal.pone.0032700.t001

in glucose tolerance or insulin sensitivity between adip-

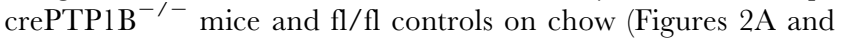
$\mathrm{C}$ ) or HFD (Figures $2 \mathrm{~B}$ and $\mathrm{D}$ ). The area under the curve of Figure 2B was also not significantly different (Figure S3); in addition, there were no significant differences in glucosestimulated insulin secretion between adip-crePTP1B ${ }^{-P_{-}}$mice and $\mathrm{fl} / \mathrm{fl}$ controls during the GTT (Figures 2E and F). Serum adiponectin, RBP4 and triglyceride levels were comparable in adip-crePTP1B ${ }^{-/-}$mice and $\mathrm{fl} / \mathrm{fl}$ controls (Table 1). Serum TNF- $\alpha$ concentrations were below the level of detection of the mouse ELISA in most control and adip-crePTP1B $\mathrm{B}^{-/-}$mice on both chow and HFD (data not shown). To further determine the flux of glucose in various insulin-sensitive tissues including brain, muscle and BAT, PET scans were performed on $\mathrm{fl} / \mathrm{fl}$ and adipcrePTP1B $^{-/-}$mice using 2-deoxy-2-(18F)-fluoro-D-glucose (FDG). In agreement with other in vivo metabolic tests, there were no significant differences in the uptake and metabolic activity of glucose in brain, muscle or BAT between $\mathrm{fl} / \mathrm{fl}$ and adip-crePTP1B ${ }^{-/-}$mice (Figures $2 \mathrm{G}$ and Table 2).
Increased serum leptin levels and reduced leptin sensitivity in HFD-fed adip-crePTP1B ${ }^{-1-}$ mice

At eight weeks HFD, leptin levels were three- to seven-fold higher in adip-crePTP1 $\mathrm{B}^{-1-}$ mice compared with adip-cre and $\mathrm{fl} / \mathrm{fl}$ controls, respectively (Table 1), suggesting increased leptin secretion with adipocyte-PTP1B deficiency and potential development of leptin resistance. Since brain-specific $\mathrm{PTP}_{1} \mathrm{~B}^{-/-}$mice also exhibited increased leptin secretion but remained leptin sensitive [18], we directly assessed leptin sensitivity in these mice. Adip-crePTP1B $\mathrm{B}^{-/-}$and $\mathrm{fl} / \mathrm{fl}$ control mice were injected twice a day with saline or leptin for three days and food intake and body weight were monitored. Compared with controls, chow-fed adip-crePTP1B ${ }^{-/-}$mice displayed no significant differences in response to leptin administration (Figure 3A), but HFD-fed adip-crePTP1B ${ }^{-/-}$ mice were significantly more resistant than controls to leptin administration, which was most apparent on day two and three of leptin injections (Figure 3B). There were no significant effects 
A

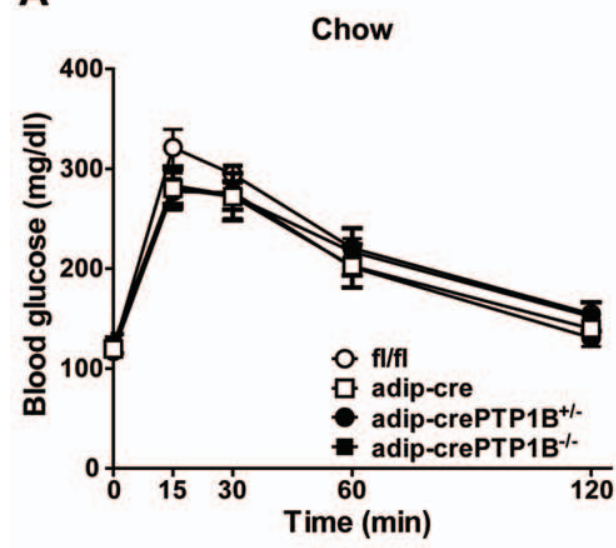

C

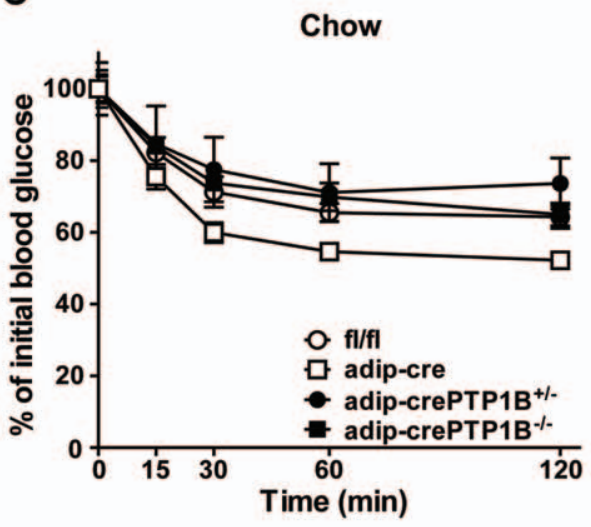

B

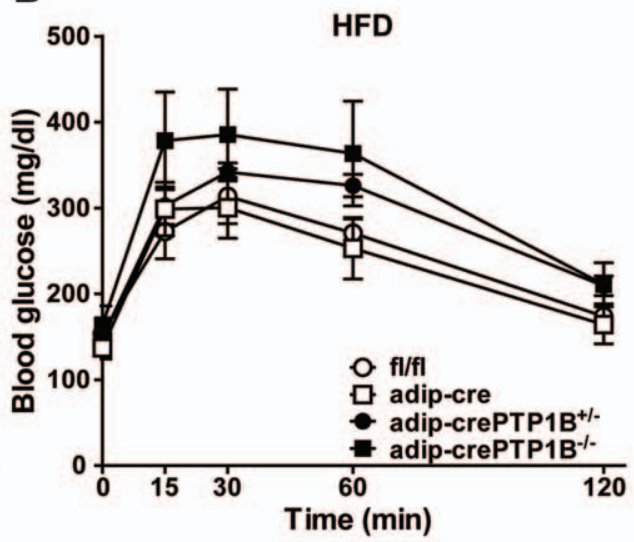

D

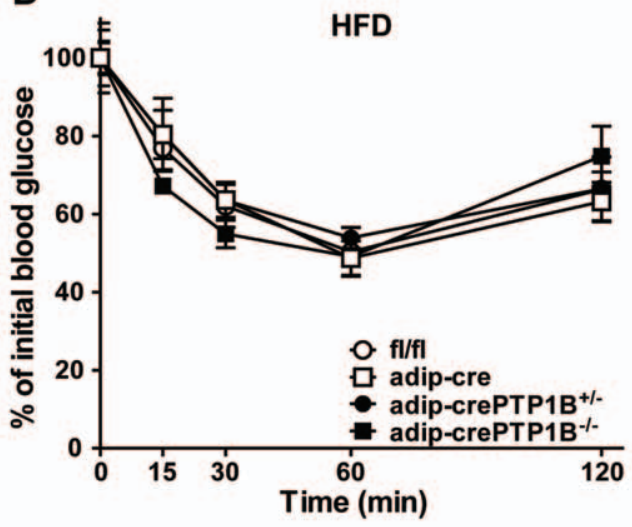

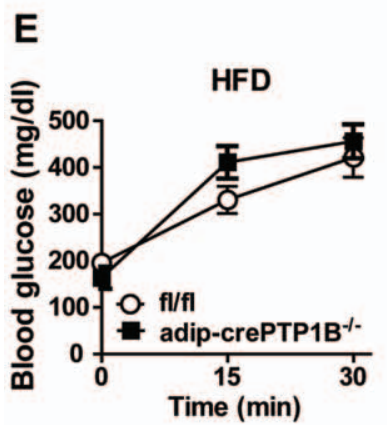
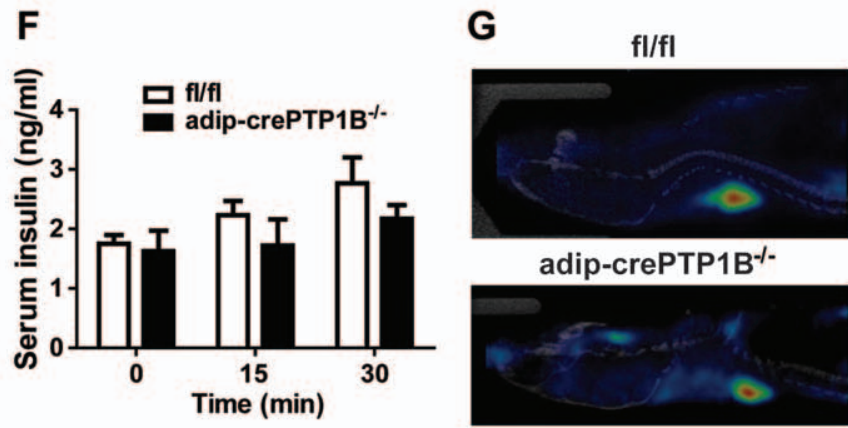

Figure 2. Glucose homeostasis in adipocyte-specific PTP1B knockout mice. $A$ : GT $(2 \mathrm{mg} / \mathrm{g}$ glucose) of mice on chow diet for 20 weeks from weaning $\mathrm{fl} / \mathrm{fl}(n=6)$; adip-cre $(n=6)$; adip-crePTP1B ${ }^{+-}(n=5)$; adip-crePTP1B ${ }^{-1-}(n=3)$. B: GTT (1.5 mg/g glucose) of mice on HFD for 19 weeks. $\mathrm{fl} / \mathrm{fl}(n=7)$; adip-cre $(n=6)$; adip-crePTP1B ${ }^{+/-}(n=5)$; adip-crePTP1B ${ }^{-1-}(n=4)$. C: ITT (Insulin $0.6 \mathrm{mU} / \mathrm{g}$ body weight) of mice on chow diet for 21 weeks from weaning. fl/fl $(n=8)$; adip-cre $(n=6)$; adip-crePTP1B ${ }^{+-}(n=5)$; adip-crePTP1B ${ }^{-1-}(n=4)$. $D:$ ITT (Insulin $1.1 \mathrm{mU} / \mathrm{g}$ body weight) of mice on HFD for 20 weeks fl/fl $(n=8)$; adip-cre $(n=6)$; adip-crePTP1B ${ }^{+/-}(n=5)$; adip-crePTP1B ${ }^{-1-}(n=4)$. E: GTT $(1.5 \mathrm{mg} / \mathrm{g})$ of mice on HFD. fl/fl $(n=5)$; adipcrePTP1B $^{-1-}(n=5)$. Glucose-stimulated insulin secretion of HFD-fed mice during GTT. fl/fl $(n=5)$; adip-crePTP1B ${ }^{-1-}(n=5)$. G: Representative PET scan image from $\mathrm{fl} / \mathrm{fl}$ (top panel) and adip-crePTP1B ${ }^{-1-}$ (bottom panel) mice. White circles $=\mathrm{fl} / \mathrm{fl}$; white squares $=$ adip-cre; black circles $=$ adipcrePTP1B $^{+/-}$; black squares $=$adip-crePTP1B ${ }^{-1-}$. White bars $=\mathrm{fl} / \mathrm{fl}$; black bars $=$ adip-crePTP1B ${ }^{-1-}$. Data are represented as mean $\pm \mathrm{SEM}$.

doi:10.1371/journal.pone.0032700.g002

of saline control injections on food intake in chow fed adip$\mathrm{crePTP}_{1} \mathrm{~B}^{-1-}$ and $\mathrm{fl} / \mathrm{fl}$ control mice (Figure S2).

Adipocyte-specific PTP1B deletion increases the basal lipogenic rate but does not affect insulin-stimulated lipogenesis in HFD-fed adip-crePTP1B ${ }^{-/-}$mice

Since insulin and leptin are known to regulate lipogenesis [37-

39], we performed lipogenesis assays in our mice to directly determine whether adipocyte-PTP1B deletion affects adipocyte insulin sensitivity, and to investigate the underlying cause(s) of increased adipocyte cell size. To evaluate the ability of adip$\mathrm{crePTP} \mathrm{B}^{-/-}$and $\mathrm{fl} / \mathrm{fl}$ control and mice to basally metabolize glucose into fatty acids, and subsequently triglycerides, (giving an indication of the level/activity of lipogenic enzymes) basal lipogenic rates were determined. On a chow diet, basal lipogenesis was not significantly different between adip-crePTP1 $\mathrm{B}^{-/-}$and control mice (Figure 3G). However, on a HFD, adip-crePTP1B ${ }^{-/-}$mice 
Table 2. PET scan average standardized uptake values from $\mathrm{fl} / \mathrm{fl}$ and adip-crePTP1 $\mathrm{B}^{-/-}$mice.

\begin{tabular}{llll}
\hline Genotype & Brain (SUV) & Muscle (SUV) & BAT (SUV) \\
\hline fl/fl & $0.20 \pm 0.02$ & $0.39 \pm 0.02$ & $0.62 \pm 0.34$ \\
adip-crePTP1B & $0.18 \pm 0.02$ & $0.35 \pm 0.02$ & $0.64 \pm 0.27$ \\
\hline $\begin{array}{l}\text { Data are means } \pm \text { SEM. } n=3-4 \text { mice/group. } \\
\text { doi:10.1371/journal.pone.0032700.t002 }\end{array}$ &
\end{tabular}

displayed significantly higher basal lipogenesis compared with $\mathrm{fl} / \mathrm{fl}$ controls (Figure 3C), consistent with the increase in adipocyte size (Figures 1F, G and H). To evaluate the insulin-sensitivity of adipocytes, a radioactive insulin-stimulated lipogenesis assay was performed on isolated adipocytes from $\mathrm{fl} / \mathrm{fl}$ and adip-crePTP1 $\mathrm{B}^{-/-}$ mice, on chow and HFD. On both chow and HFD, isolated adipocytes from adip-crePTP1B ${ }^{-/-}$mice displayed no differences in the insulin-stimulated lipogenic response compared with adipocytes from $\mathrm{fl} / \mathrm{fl}$ control mice (Figures $3 \mathrm{D}$ and E), suggesting no differences in glucose uptake.
A

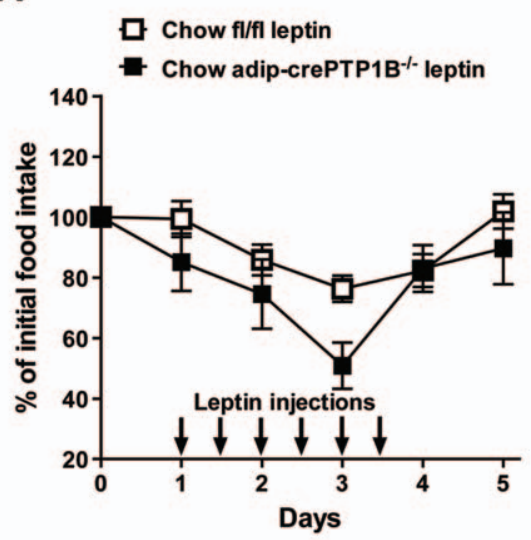

B

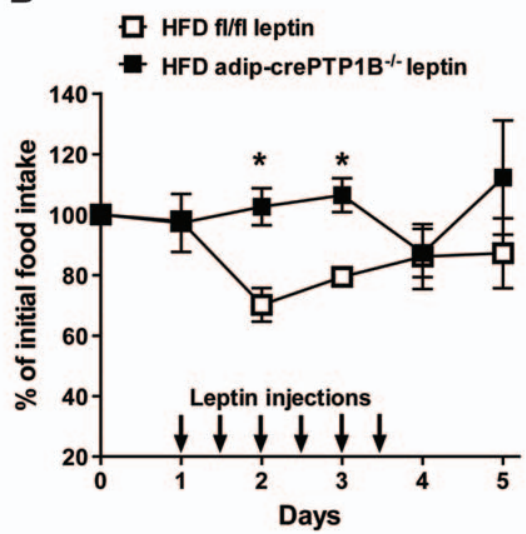

C

C $\square$ fl/fl

adip-crePTP1B $\%$

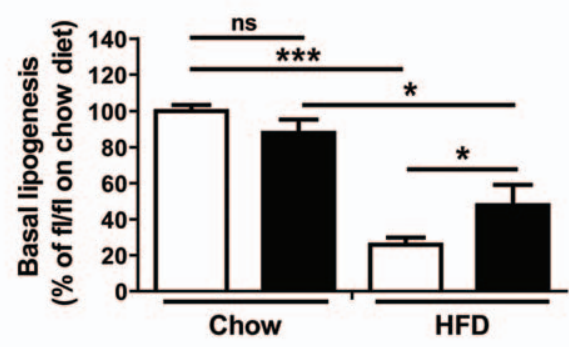

D E

Chow
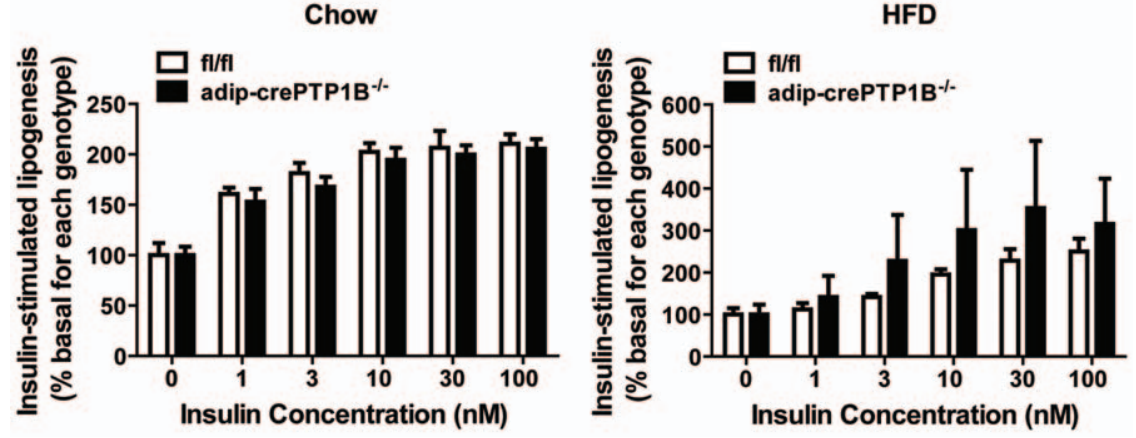

Figure 3. Decreased leptin sensitivity and increased lipogenesis in HFD-fed adip-crePTP1B ${ }^{-1-}$ mice. A: Leptin sensitivity, as measured by the percentage change in food intake after leptin administration in chow-fed adip-crePTP1B ${ }^{-/-}(n=5)$ and fl/fl control mice $(n=5)$. B: Leptin sensitivity in HFD-fed adip-crePTP1B ${ }^{-1-}(n=3)$ and fl/fl control mice $(n=3)$. C: Basal lipogenesis in chow and HFD-fed adip-crePTP1B ${ }^{-/-}(n=3)$ and fl/ $\mathrm{fl}$ control mice $(n=3)$. $D$ : Insulin-stimulated lipogenesis of chow-fed adip-crePTP1B ${ }^{-1-}(n=4)$ and fl/fl control mice $(n=4)$. E: Insulin-stimulated lipogenesis of HFD-fed adip-crePTP1B ${ }^{-1-}(n=3)$ and fl/fl control mice $(n=3)$. White squares = chow fl/fl leptin; white triangles= HFD fl/fl leptin; black squares $=$ chow adip-crePTP1B ${ }^{-1-}$ leptin; black triangles $=$ HFD adip-crePTP1B ${ }^{-1-}$ leptin. White bars $=$ fl/fl; black bars $=$ adip-crePTP1B $^{-\prime-}$. Data are represented as mean \pm SEM; Data were analyzed using a two-way ANOVA with Bonferroni multiple comparisons post-tests $\left({ }^{*} P \leq 0.05 ;{ }^{* * *} P<0.001\right)$. doi:10.1371/journal.pone.0032700.g003 
Decreased in vivo insulin signaling in adipose tissue from HFD-fed adip-crePTP1B ${ }^{-/-}$mice

To investigate the molecular consequences of adipocyte-specific PTP1B deletion in WAT and BAT, mice were injected with either saline or insulin $(10 \mathrm{mU} / \mathrm{g}$ body weight), and various components of the insulin signaling pathway were analyzed in epididymalWAT (E-WAT), subcutaneous-WAT (SQ-WAT) and BAT. HFDfeeding of fl/fl controls led to significantly higher PTP1B levels in E-WAT (Figures 4A and B) and BAT (Figure 5C) compared with chow-fed $\mathrm{fl} / \mathrm{fl}$ controls. In chow-fed mice, insulin-stimulated phosphorylation of the IR at sites Y1162/63 and Y1158, as well as total IR tyrosyl phosphorylation (measured following immunoprecipitation of the IR and anti-pY blotting) were comparable in E-WAT from both groups of mice (Figures 4A, C, D). However, phosphorylation of IRS- 1 at site Y608 and Akt/PKB at site S473 trended to be higher in E-WAT from chow-fed adip-crePTP1B ${ }^{-\prime}$

mice compared with controls $(P=0.06$ and $P=0.08$, respectively) (Figures 4A, E and F). Notably, relative to HFD-fed controls, insulin-evoked IR tyrosyl phosphorylation in E-WAT was significantly diminished in adip-crePTP1B ${ }^{-/-}$mice on HFD (Figures 4A and $\mathrm{C}$ ). There was a similar trend towards decreased phosphorylation at IR site Y1158 and pAkt/PKB site S473 in adip-crePTP $1 \mathrm{~B}^{-/-}$mice $(P=0.07$ and $P=0.08$, respectively) (Figures 4A, D and F). There were no differences in the phosphorylation of the IR on site Y1162/63, IRS-1 (S636/639) ERK1/2 (T202/Y204), GSK-3 $\alpha$ (S21), GSK-3 $\beta$ (S9), AMPK (T172), S6 ribosomal protein (S235/236), S6 ribosomal protein (S240/244), p70S6K (T389) or mTOR (S2448) on chow or HFD between adip-crePTP1B ${ }^{-/-}$and control mice (Figure 4A). Total protein levels of other tyrosine phosphatases, such as TC-PTP and SHP2, were comparable in E-WAT of adip-crePTP1B ${ }^{-1-}$ and control mice on both diets (Figure 4A). In SQ-WAT the phosphorylation of Akt/PKB (S473) was similar on chow, but significantly decreased in HFD-fed adip-crePTP1B ${ }^{-/-}$mice compared with controls (Figures $5 \mathrm{~A}$ and $\mathrm{B}$ ). However, there were no differences in SQ-WAT phosphorylation of the IR (Y1162/63) or S6 ribosomal protein (S235/236) between groups on both diets (Figure 5A). Furthermore, BAT phosphorylation levels of the IR (Y1162/63), Akt/PKB (S473) and S6 ribosomal protein (S235/ 236) were comparable between adip-crePTP1B ${ }^{->-}$and control mice on both diets (Figure 5C).

\section{No effect of adipocyte-PTP1B deletion on insulin signaling in isolated adipocytes}

To investigate whether the decreased insulin signaling observed in epididymal white adipose tissue in vivo was directly due to PTP1B deletion in adipocytes, insulin signaling stimulations were performed ex vivo on isolated adipocytes from control and adipcrePTP $1 \mathrm{~B}^{-/-}$mice. Isolated adipocytes were stimulated with $0 \mathrm{nM}, 1 \mathrm{nM}$ (data not shown) $10 \mathrm{nM}$ or $100 \mathrm{nM}$ of insulin, and key components of the insulin signaling pathway, which were affected in vivo, were analyzed. There were no differences in the phosphorylation of the insulin receptor, Akt/PKB or S6 ribosomal protein between genotypes on either chow or HFD (Figures 6A and $\mathrm{B})$.

\section{Increased lipogenic markers in HFD-fed adip-crePTP1B ${ }^{-/}$ - mice}

The sterol regulatory element-binding proteins (SREBPs) coordinately activate the expression of over 30 genes involved in the uptake of fatty acids, triglycerides and phospholipids [40]. Expression of Srebp-1c and its target gene fatty acid synthase (Fas) were significantly higher in HFD-fed adip-crePTP1B ${ }^{-/-}$mice compared with $\mathrm{fl} / \mathrm{fl}$ controls (Figures $7 \mathrm{~A}$ and $\mathrm{B}$ ), consistent with increased basal lipogenesis (Figure 3G) and an increase in adipocyte size (Figure $1 \mathrm{G}$ and $\mathrm{H}$ ). Srebp2 and peroxisome proliferator-activated receptor gamma (Ppar- $\gamma$ ) expression levels were comparable between groups on both chow and HFD (Figures 7C and D). Phosphoenolpyruvate carboxykinase (Pepck) expression levels were comparable between groups on a chow diet but there was a trend $(P=0.06)$ on a HFD towards higher Pepck mRNA levels in adip-crePTP1B ${ }^{-/-}$mice compared to $\mathrm{fl} / \mathrm{fl}$ controls (Figure 7E). Hypoxia-inducible factor-1 alpha (Hif-1 $\alpha$ ) expression levels were significantly higher in adip-crePTP1B ${ }^{-/-}$ mice compared to fl/fl controls on a chow diet. As expected, HFDfeeding increased Hif- $1 \alpha$ mRNA levels in both groups of mice, however there was a trend $(P=0.07)$ for HFD-fed adip$\mathrm{crePTP} \mathrm{B}^{-/-}$mice to have higher $H$ if- $1 \alpha \mathrm{mRNA}$ levels compared to $\mathrm{fl} / \mathrm{fl}$ controls (Figure $7 \mathrm{~F}$ ). The mRNA expression of the adipokine leptin was significantly higher in adipose-tissue from HFD-fed adip-crePTP1B ${ }^{-/-}$mice compared with $\mathrm{fl} / \mathrm{fl}$ controls (Figure 7G), consistent with increased circulating serum leptin levels in these mice (Table 1). Adiponectin and Tnf- $\alpha$ gene expression were comparable between adip-crePTP1B ${ }^{-/-}$mice and controls on both chow and HFD (Figures $7 \mathrm{H}$ and I).

\section{Discussion}

Adipose-PTP1B ${ }^{-/-}$mice were generated previously using the aP2-promoter in an attempt to evaluate the effect(s) of PTP1B on body mass control in adipose tissue. Despite only $\sim 50 \%$ reduction of PTP1B levels in white adipocytes, aP2-crePTP1B ${ }^{-/-}$mice displayed significantly increased body weight on a HFD compared with $\mathrm{PTP}_{1 \mathrm{~B}}^{\mathrm{fl} / \mathrm{fl}}$ littermate controls [18]. However, whether adipocyte-specific PTP1B was the true cause of increased weight gain in these mice is unclear as the aP2-promoter cassette is also active in other cell types, such as macrophages, osteoblasts and cardiomyocytes [21,22]. Here we used adiponectin-cre mice, which express Cre selectively in adipocytes [28] (Figure 1A).

As with muscle- and liver-specific PTP1B deletion, adipocytespecific PTP1B deletion did not affect body weight or adiposity in mice fed chow or HFD. This would suggest that PTP1B deletion in other cell types might be the cause of the body weight effects observed in aP2-crePTP1B $\mathrm{B}^{-/-}$mice. It is also possible that the disparate weight differences between $\mathrm{aP} 2-\mathrm{crePTP}_{\mathrm{B}} \mathrm{B}^{-1-}$ and adip-

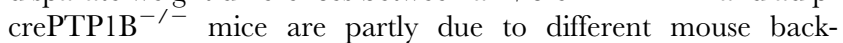
grounds, as the aP2-crePTP1B ${ }^{-/-}$mice were on a mixed $129 \mathrm{~Sv} / \mathrm{J}$ $\mathrm{X}$ C57BL/6J background whereas the adip-crePTP1B ${ }^{-/-}$mice were backcrossed to $\mathrm{C} 57 \mathrm{BL} / 6$ background for several generations.

Chow and HFD-fed adip-crePTP1B ${ }^{-/-}$mice were found to have larger epididymal adipocytes than $\mathrm{fl} / \mathrm{fl}$ controls. However, smaller adipocytes were observed in mice with a global PTP1B deletion compared with controls [16,25]. This suggests that adipocyte-PTP1B deletion did not contribute to the previously observed decrease in fat mass and adipocyte size observed in global $\mathrm{PTP}_{1 \mathrm{~B}^{-/-}}$mice; the latter most likely was caused by neuronal-PTP1B deletion [18].

Intriguingly, PTP1B has been shown to be involved in adipocyte differentiation. One study has shown that inhibitors resulting in PTP1B deficiency in fat, decreased genes involved in adipocyte differentiation [41]. Furthermore, a more recent study demonstrated that inhibition of PTP1B in 3T3-L1 adipocytes inhibits adipogenesis [42]. However, this does not appear to be the case in BAT. Two studies have demonstrated that PTP1B-deficiency in BAT promotes adipocyte differentiation and adipogenesis and protects against apoptosis-inducing stimuli $[43,44]$. Therefore, in the current study, it is possible that PTP1B deletion has led to an 


\section{Epididymal WAT}

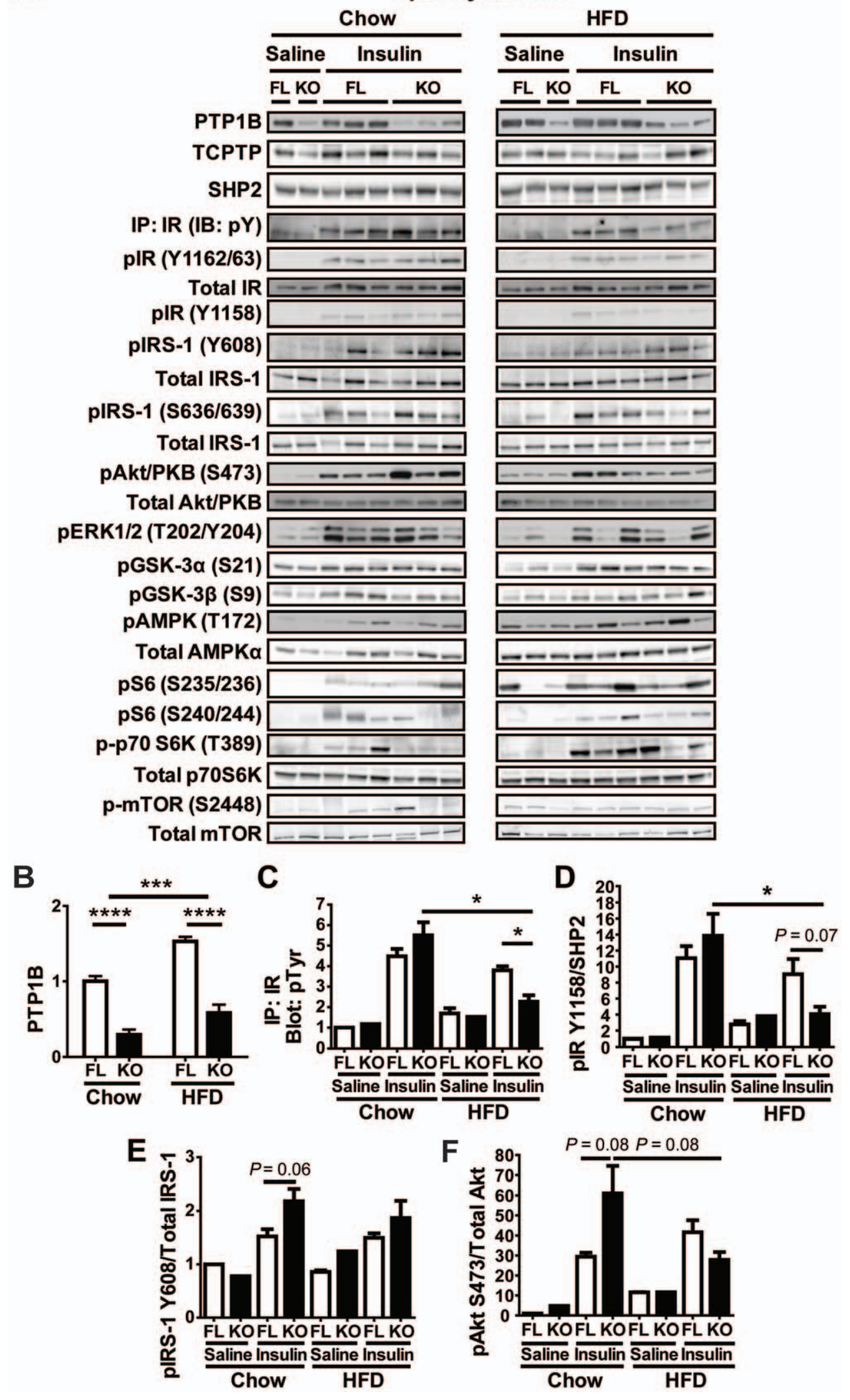

Figure 4. Reduced in vivo insulin signaling in epididymal white adipose tissue from HFD-fed adip-crePTP1B ${ }^{-1-}$ mice. $A$ : Epididymal white adipose tissue immunoblots of insulin signaling components in chow- and HFD-fed fl/fl and adip-crePTP1B ${ }^{-/-}$(KO) and fl/fl (FL) mice after injection with saline or insulin $(10 \mathrm{mU} / \mathrm{kg})$. B: PTP1B levels and deletion efficiency of fl/fl $(n=4-5)$ and adip-crePTP1B ${ }^{-/-}$mice $(n=4)$ in epididymal white adipose tissue under chow- and HFD-fed conditions. Graphs C to F show phosphorylation levels of the indicated proteins in epididymal white 
adipose tissue after saline or insulin (10 mU/kg) injection of chow- or HFD-fed fl/fl and adip-crePTP1 $\mathrm{B}^{-/-}$mice, as indicated. Phosphorylated proteins

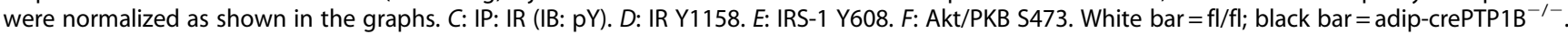
Data are represented as mean \pm SEM; data were analyzed using two-way ANOVA with Bonferroni multiple comparisons post-tests to compare between diets, and two-tailed Student's $t$ test to compare between different genotypes on the same diet $\left({ }^{*} P<0.05 ;{ }^{* * P} P<0.01 ;{ }^{* * *} P<0.001\right.$; $* * * * P<0.0001$ )

doi:10.1371/journal.pone.0032700.g004

inhibition of adipocyte differentiation in WAT, resulting in cells which have become enlarged to compensate for storing excess energy from both chow and HFD.

However, the mechanism causing this increase in adipocyte size is not clear. Another possibility for the increased cell size could be, at least partly, due to increased basal lipogenesis and elevated

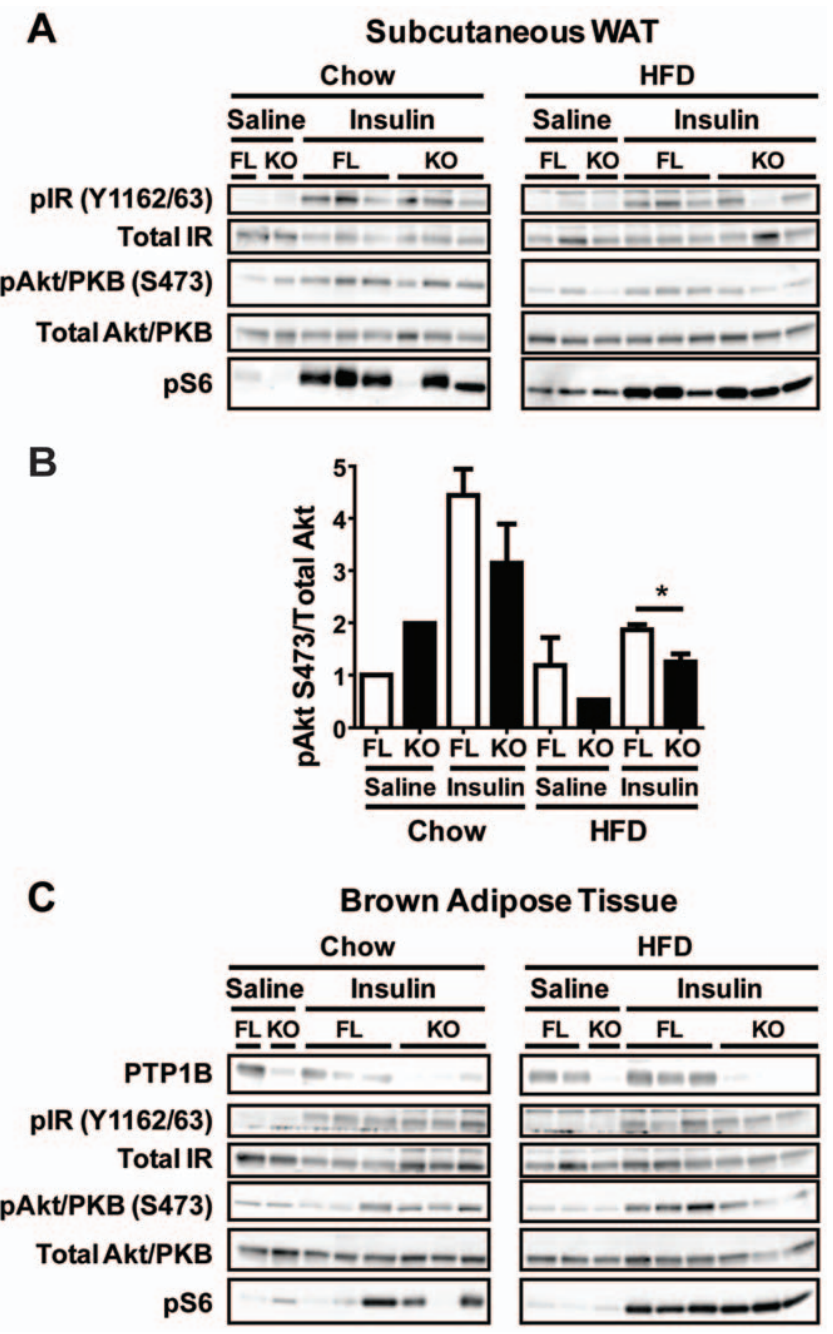

Figure 5. Reduced in vivo insulin signaling in subcutaneous white adipose tissue from HFD-fed adip-crePTP1B ${ }^{-1-}$ mice. $A$ : Subcutaneous white adipose tissue immunoblots of insulin signaling components in chow- and HFD-fed fl/fl and adip-crePTP1B ${ }^{-1-}$ (KO) and $\mathrm{fl} / \mathrm{fl}(\mathrm{FL})$ mice after injection with saline or insulin $(10 \mathrm{mU} / \mathrm{kg})$. $B$ : Akt/PKB S473 phosphorylation levels normalized to total Akt/PKB in subcutaneous white adipose tissue after saline or insulin $(10 \mathrm{mU} / \mathrm{kg})$ injection of chow- or HFD-fed fl/fl (FL) and adip-crePTP1B ${ }^{-1-}$ mice (KO). C: Brown adipose tissue immunoblots of insulin signaling components in chowand HFD-fed $\mathrm{fl} / \mathrm{fl}$ and adip-crePTP1B ${ }^{-/-}(\mathrm{KO})$ and $\mathrm{fl} / \mathrm{fl}(\mathrm{FL})$ mice after injection with saline or insulin $(10 \mathrm{mU} / \mathrm{kg})$. White $\mathrm{bar}=\mathrm{fl} / \mathrm{fl}$; black $\mathrm{bar}=$ adip-crePTP1B ${ }^{-/-}$. Data are represented as mean $\pm \mathrm{SEM}$; data were analyzed using two-tailed Student's $t$ test $\left({ }^{*} P<0.05 ;{ }^{*} P<0.01\right)$. doi:10.1371/journal.pone.0032700.g005 expression of Srebp-1c and Fas. Given that adip-crePTP1B ${ }^{-/-}$ mice have decreased insulin signaling on HFD, and that leptin normally inhibits lipogenesis by stimulating fatty acid oxidation via negative regulation of Srebp-1c [37,38], it is surprising that Srebp-1c and Fas gene expression are increased compared with controls. Interestingly however, an opposite and similarly paradoxical phenotype was observed in liver-specific PTP1B knockout mice: they displayed increased hepatic insulin signaling and decreased expression levels of hepatic Srebp-1c, Fas and other lipogenic markers $[5,45]$. In the liver, PTP1B may regulate Srebp-1a and Srebp-1c mRNA expression via phosphatase 2A (PP2A) activity [46]. It is suspected that PTP1B may affect Srebp-1 gene expression via a non-insulin signaling pathway in the liver [47], which might also be the case in adipocytes.

Interestingly, in vivo over-expression of Pepck in adipose tissue was shown to increase glyceroneogenesis and fatty acid reesterification, leading to increased adipocyte size and fat mass [48]. Mice with an adipocyte-PTP1B deletion displayed increased expression of Pepck on a HFD compared with $\mathrm{fl} / \mathrm{fl}$ controls, suggesting that the increased adipocyte size may also be partly due to increased glyceroneogenesis and fatty acid re-esterification in these mice.

During the early stages of obesity, hypoxic conditions cause an increase in the level of Hif- $1 \alpha$ expression in mice on a HFD and in genetically obese $o b / o b$ mice [49]. Hif- $1 \alpha$ over-expression in vivo has been shown to lead to increased adipocyte cell size and it has been proposed that Hif- $1 \alpha$ upregulation represents one of the earliest events in adipose tissue expansion and dysfunction [49]. Indeed, HFD-feeding led to increased Hif- $1 \alpha$ expression in both groups of mice. Interestingly however, we found that Hif- $1 \alpha$ expression was higher in chow and HFD-fed adip-crePTP1B ${ }^{-/-}$mice compared with $\mathrm{fl} / \mathrm{fl}$ controls, suggesting that these mice are more prone to hypoxia-induced adipose tissue expansion, which may have also contributed to enlarged adipocytes and increased leptin secretion. Furthermore, a recent study which demonstrated that HIF binds to the PTP1B promoter and reduces PTP1B expression, and proposed that there was a HIF-regulated VHL-PTP1B-Src signaling axis in renal cell carcinoma (RCG) cells, suggests that there is a relationship between $H I F-1$ expression and PTP1B signaling [50].

The expression and release of leptin have been shown to depend on adipocyte cell size in rodents and humans [51,52]. In HFD-fed mice, adipocyte-specific PTP1B deletion increased serum leptin levels seven-fold and leptin mRNA expression six-fold in comparison to $\mathrm{fl} / \mathrm{fl}$ controls, which may be due to the increased volume of adipocytes in these mice, as body weight and ad libitum food intake were comparable between HFD-fed adip-crePTP1B ${ }^{-/-}$and control mice. An increase in leptin secretion was also observed in neuronal-specific PTP1B knockout mice, which displayed increased serum leptin levels but remained leptin hypersensitive [18]. Reduced suppression of food intake in response to exogenous leptin in HFD-fed adip-crePTP1B ${ }^{-/-}$mice suggests that they were more leptin resistant than their HFD-fed controls. PTP1B clearly appears to play an important role in leptin secretion but the pathways involved remain to be determined.

Adipose tissue has been shown to play an important role in glucose homeostasis via secretion of adipokines and accounts for 


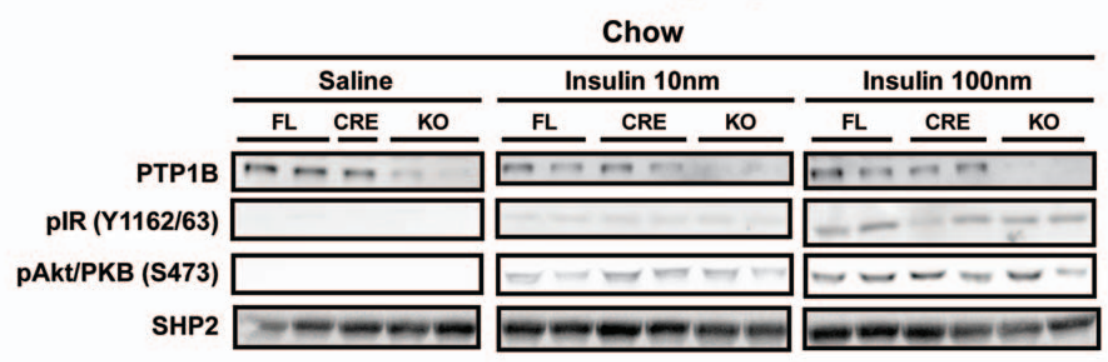

B

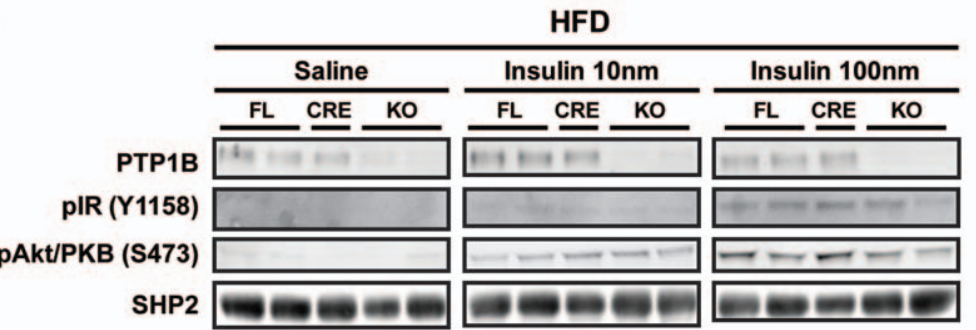

Figure 6. No effect of adipocyte-PTP1B deletion on insulin signaling in isolated adipocytes. $A$ : Immunoblots of insulin-stimulated ( $0 \mathrm{nM}$, $10 \mathrm{nM}$ or $100 \mathrm{nM}$ insulin) isolated epididymal adipocytes from chow-fed control and adip-crePTP1B ${ }^{-1-}$ mice. $B$ : Immunoblots of insulin-stimulated ( $0 \mathrm{nM}, 10 \mathrm{nM}$ or $100 \mathrm{nM}$ insulin) isolated epididymal adipocytes from HFD-fed control and adip-crePTP1B ${ }^{-1-}$ mice. doi:10.1371/journal.pone.0032700.g006

$\sim 10-15 \%$ of postprandial glucose uptake [53]. Large adipocytes exhibit reduced glucose uptake and are less insulin-sensitive than small adipocytes as they become enriched with large lipid droplets [54]. Fasted blood glucose levels after 8 and 14 weeks of HFD, and HOMA-IR after 14 weeks HFD, were significantly higher in adip$\mathrm{crePTP}_{1} \mathrm{~B}^{-/-}$mice than $\mathrm{fl} / \mathrm{fl}$ controls suggesting mild glucose intolerance in these mice. However, adip-crePTP1B ${ }^{-/-}$mice showed no alteration in serum adipokines (other than leptin), despite larger adipocytes and increased lipogenesis.

Reports of the effect(s) of adipose tissue PTP1B-deficiency on insulin signaling are conflicting. In vivo antisense oligonucleotide treatment, which decreased adipose-PTP1B, elicited some improvements in insulin signaling [26,27]. However, over-expression of PTP1B in differentiated adipocytes had minimal effects on insulin signaling [23]. Furthermore, adipose tissue-insulin signaling was not different in global PTP1B ${ }^{-\prime-}$ mice relative to controls [17]. In contrast, in another study, basal hyper-phosphorylation of p70S6K was observed in the adipose tissue of globally PTP1Bdeficient mice, which was described as the cause of decreased insulin-stimulated phosphorylation of IRS- 1 and decreased activity of $\mathrm{Akt} / \mathrm{PKB}$, leading to adipose-specific insulin resistance in $\mathrm{PTP}_{1} \mathrm{~B}^{-/-}$mice [25]. Consistent with the latter studies, we show here that insulin-stimulated phosphorylation of IR and Akt/PKB, under HFD-feeding conditions, is impaired in mice with an adipocyte-specific PTP1B deletion. Interestingly, leptin has been shown to impair insulin signaling in rat adipocytes [55], which is also consistent with these observations. It is possible that the increases in serum leptin, in the absence of PTP1B in adipocytes, and the potential of signaling crosstalk, may be confounding detection of predicted changes in insulin signaling in vivo. However, since we did not observe any differences between groups in IR phosphorylation, or that of the downstream components, in isolated adipocytes under different insulin concentrations, this confirms our in vivo findings that PTP1B does not appear to be the main IR phosphatase nor be a negative regulator of insulin signaling in adipocytes. In addition, adipocyte-PTP1B deletion did not result in any differences in the phosphorylation of p70S6K, S6 ribosomal protein, IRS-1, mTOR or a number of other insulin signaling pathway components in our studies. Such differences in findings may be due to altered cross-talk between the adipose tissue and other tissues, such as the liver and the central nervous system, in global $\mathrm{PTP} 1 \mathrm{~B}^{-/-}$mice.

We therefore suggest that PTP1B deletion in adipocytes enhances basal lipogenesis and fatty acid re-esterification via a non-classical insulin signaling pathway, by increasing lipogenic (Srebp-1c, Fas) and gluconeogenic (Pepck) mRNA expression, which subsequently leads to increased lipid storage and enlarged adipocytes. This increased adipocyte size, combined with increased Hif-1 $\alpha$ gene expression, results in hypoxia-induced adipose tissue dysfunction and leads to augmented leptin secretion, which dampens adipocyte-insulin signaling; finally leading to leptin resistance and mildly elevated fasting blood glucose. Our findings and those of Ruffolo et al. suggest that some compensatory mechanism(s), such as the up-regulation of another protein tyrosine phosphatase may be involved in regulating adipocyteinsulin signaling $[17,25]$. T-cell protein-tyrosine phosphatase (TCPTP) is a ubiquitous tyrosine-specific phosphatase with a high degree of similarity to PTP1B [56]. Furthermore, TC-PTP has been shown to coordinately regulate insulin signaling with PTP1B and act to control common and distinct insulin signaling pathways within the same cells [56]. In the current study, TC-PTP was not up-regulated by PTP1B deletion. Similarly, no changes in SHP2 levels were observed in adip-crePTP1B ${ }^{-1}$ mice. However, it is still possible that some other protein tyrosine phosphatase(s) may play a role as a negative regulator of IR signaling in adipocytes.

Overall, tissue-specific knockout studies of PTP1B have revealed key roles for brain-, liver- and muscle-PTP1B in the regulation of global energy and glucose homeostasis. However, adipocytePTP1B primarily appears to only locally regulate lipogenic gene expression, adipocyte cell size, and leptin secretion and does not appear to play a major role in regulating body weight/adiposity or whole body glucose homeostasis. 

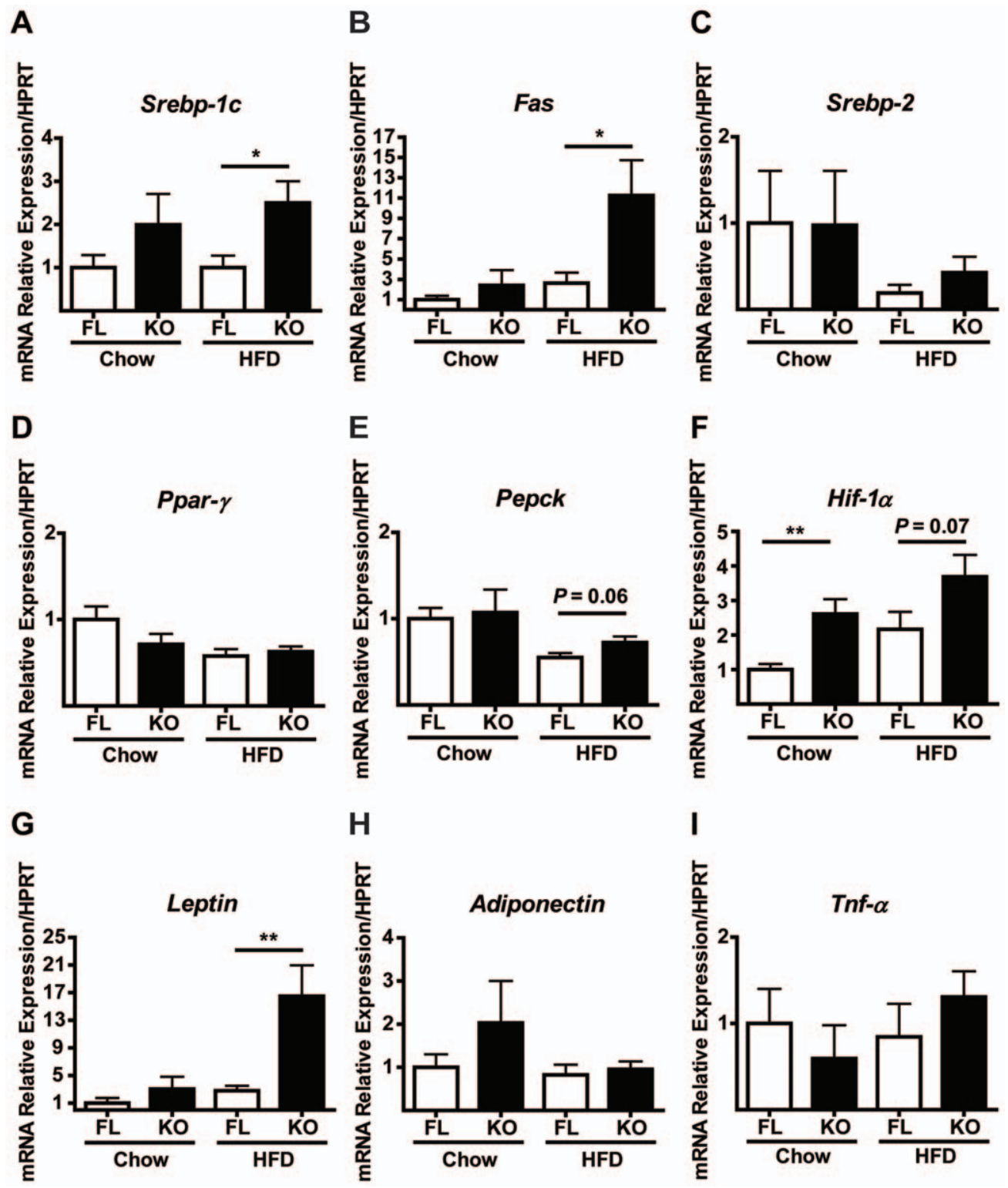

Figure 7. Increased lipogenic gene expression in HFD-fed adip-crePTP1B ${ }^{-1-}$ mice. Graphs A to I show relative mRNA levels of the indicated genes in epididymal WAT, measured by quantitative real-time PCR and normalized against Hprt mRNA. Chow-fed adip-crePTP1B ${ }^{-1-}(n=4)$ and chowfed fl/fl control mice $(n=13)$ were compared to HFD-fed adip-crePTP1B ${ }^{-1-}(n=4)$ and HFD-fed fl/fl control mice $(n=15)$. A: Srebp-1c. B: Fas. C: Srebp-2. D: Ppar- $\gamma$. E: Pepck. F: Hif-1 $\alpha$. G: Leptin. H: Adiponectin. I: Tnf- $\alpha$. White bar $=\mathrm{fl} / \mathrm{fl} ;$ black bar $=$ adip-crePTP1B ${ }^{-1-}$. Data are represented as mean \pm SEM; data were analyzed using two-tailed Student's t test $\left({ }^{*} P<0.05 ;{ }^{*} P<0.01\right)$ doi:10.1371/journal.pone.0032700.g007

\section{Supporting Information}

Figure S1 PTP1B deletion of fl/fl control, adip-crealone control and adip-crePTP1B ${ }^{+\prime-}$ mice. $\mathrm{PTP} 1 \mathrm{~B}$ deletion efficiency of HFD-fed fl/fl (FL), adip-cre-alone (CRE) and adipcrePTP1B $^{+/-}($HET $)$mice in epididymal WAT.

(TIF)

Figure S2 Saline control injections to leptin sensitivity experiment. No significant effect on food intake after saline control injections in chow fed adip-crePTP1B ${ }^{-/-}$and $\mathrm{fl} / \mathrm{fl}$ control mice ( $n=3$ mice/group). White circles = chow $\mathrm{fl} / \mathrm{fl}$ saline; black circles $=$ chow adip-crePTP1B ${ }^{-/-}$saline. Data are represented as mean \pm SEM.

(TIF)
Figure S3 Area under the curve of Figure 2B. No significant differences between groups. PTP1B deletion does not significantly affect glucose clearance following a glucose bolus. White bars $=\mathrm{fl} / \mathrm{fl}$; diagonally striped bars = adip-cre; horizontally striped bars $=$ adip-crePTP $1 \mathrm{~B}^{+/-}$; black bars $=$adip-crePTP $1 \mathrm{~B}^{-/-}$. Data are represented as mean \pm SEM. (TIF)

Figure S4 Adipocyte morphology in subcutaneous and peri-renal fat pads. No differences of subcutaneous or perirenal adipocyte cell size between HFD-fed adip-crePTP1B ${ }^{-/-}$ mice $(\mathrm{KO})$ and $\mathrm{fl} / \mathrm{fl}(\mathrm{FL})$ control mice. $n=4$ mice/group. White bars $=\mathrm{fl} / \mathrm{fl}$; black bars $=$ adip-crePTP1B ${ }^{-/-}$. Data are represented as mean \pm SEM.

(TIF) 
Table S1 Real time quantitative PGR primer sequences for gene expression analysis and PGR primer sequences for genotyping.

(DOCX)

\section{Acknowledgments}

We greatly appreciate the gift of the adiponectin-cre mice from Dr. Evan Rosen (Beth Israel Deaconess Medical Centre and Harvard Medical School, Boston, USA).

\section{References}

1. Biddinger S, Kahn C (2006) From mice to men: insights into the insulin resistance syndromes. Annu Rev Physiol 68: 123-158.

2. Unger R (1995) Lipotoxicity in the pathogenesis of obesity-dependent NIDDM. Genetic and clinical implications. Diabetes 44: 863-870.

3. Herman MA, Kahn BB (2006) Glucose transport and sensing in the maintenance of glucose homeostasis and metabolic harmony. J Clin Invest 116: 1767-1775.

4. Rosen ED, Spiegelman BM (2006) Adipocytes as regulators of energy balance and glucose homeostasis. Nature 444: 847-853.

5. Delibegovic M, Zimmer D, Kauffman C, Rak K, Hong E, et al. (2009) Liverspecific deletion of protein-tyrosine phosphatase 1B (PTP1B) improves metabolic syndrome and attenuates diet-induced endoplasmic reticulum stress. Diabetes 58: $590-599$.

6. Kobayashi K, Inoguchi T (2005) Adipokines: therapeutic targets for metabolic syndrome. Curr Drug Targ 6: 525-529.

7. Shulman GI (2000) Cellular mechanisms of insulin resistance. J Clin Invest 106: 171-176.

8. Taniguchi CM, Emanuelli B, Kahn CR (2006) Critical nodes in signalling pathways: insights into insulin action. Nat Rev Mol Cell Biol 7: 85-96.

9. Dorrestijn J, Van Bussel F, Maasen J, Gomes de Mesquita D (1998) Early steps in insulin action. Arch Physiol Biochem 106: 269-289.

10. Saltiel AR, Kahn CR (2001) Insulin signalling and the regulation of glucose and lipid metabolism. Nature 414: 799-806.

11. Sarbassov DD, Guertin DA, Ali SM, Sabatini DM (2005) Phosphorylation and regulation of Akt/PKB by the rictor-mTOR complex. Science 307: 1098-1101.

12. Kohn AD, Summers SA, Birnbaum MJ, Roth RA (1996) Expression of a constitutively active akt Ser/Thr kinase in 3T3-L1 adipocytes stimulates glucose uptake and glucose transporter 4 translocation. J Biol Chem 271: 31372-31378.

13. Yip SC, Saha S, Chernoff J (2010) PTP1B: a double agent in metabolism and oncogenesis. Trends Biochem Sci 35: 442-449.

14. Woodford-Thomas TA, Rhodes JD, Dixon JE (1992) Expression of a protein tyrosine phosphatase in normal and v-src-transformed mouse 3T3 fibroblasts. J Cell Biol 117: 401-414.

15. Frangioni JV, Beahm PH, Shifrin V, Jost CA, Neel BG (1992) The nontransmembrane tyrosine phosphatase PTP-1B localizes to the endoplasmic reticulum via its 35 amino acid C-terminal sequence. Cell 68: 545-560.

16. Klaman LD, Boss O, Peroni OD, Kim JK, Martino JL, et al. (2000) Increased energy expenditure, decreased adiposity, and tissue-specific insulin sensitivity in protein-tyrosine phosphatase 1B-deficient mice. Mol Cell Biol 20: 5479-5489.

17. Elchebly M, Payette P, Michaliszyn E, Cromlish W, Collins S, et al. (1999) Increased insulin sensitivity and obesity resistance in mice lacking the protein tyrosine phosphatase-1B gene. Science 283: 1544-1548.

18. Bence K, Delibegovic M, Xue B, Gorgun C, Hotamisligil G, et al. (2006) Neuronal PTP1B regulates body weight, adiposity and leptin action. Nat Med 12: $917-924$.

19. Delibegovic M, Bence KK, Mody N, Hong EG, Ko HJ, et al. (2007) Improved glucose homeostasis in mice with muscle-specific deletion of protein-tyrosine phosphatase 1B. Mol Cell Biol 27: 7727-7734.

20. Banno R, Zimmer D, De Jonghe BC, Atienza M, Rak K, et al. (2010) PTP1B and SHP2 in POMC neurons reciprocally regulate energy balance in mice. J Clin Invest 120: 720-734.

21. Wang ZV, Deng Y, Wang QA, Sun K, Scherer PE (2010) Identification and characterization of a promoter cassette conferring adipocyte-specific gene expression. Endocrinology 151: 2933-2939.

22. Mao J, Yang T, Gu Z, Heird WC, Finegold MJ, et al. (2009) aP2-cre-mediated inactivation of acetyl-CoA carboxylase 1 causes growth retardation and reduced lipid accumulation in adipose tissues. Proc Natl Acad Sci U S A 106: $17576-17581$

23. Venable CL, Frevert EU, Kim YB, Fischer BM, Kamatkar S, et al. (2000) Overexpression of protein-tyrosine phosphatase-1B in adipocytes inhibits insulin-stimulated phosphoinositide 3-kinase activity without altering glucose transport or Akt/Protein kinase B activation. J Biol Chem 275: 18318-18326.

24. Kenner KA, Anyanwu E, Olefsky JM, Kusari J (1996) Protein-tyrosine phosphatase $1 \mathrm{~B}$ is a negative regulator of insulin-and insulin-like growth factor-I-stimulated signaling. J Biol Chem 271: 19810-19816.

25. Ruffolo SC, Forsell PKA, Yuan X, Desmarais S, Himms-Hagen J, et al. (2007) Basal activation of p70S6K results in adipose-specific insulin resistance in protein-tyrosine phosphatase 1B-/-mice. J Biol Chem 282: 30423-30433.

\section{Author Contributions}

Conceived and designed the experiments: MD NM. Performed the experiments: CO AC AA LG RJ EKL GDM AW MD. Analyzed the data: CO AC AA LG RJ EKL GDM AW NM MD. Contributed reagents/ materials/analysis tools: RJ OG AW KKB BBK BGN NM MD. Wrote the paper: $\mathrm{CO} \mathrm{MD}$.

26. Rondinone CM, Trevillyan JM, Clampit J, Gum RJ, Berg C, et al. (2002) Protein tyrosine phosphatase $1 \mathrm{~B}$ reduction regulates adiposity and expression of genes involved in lipogenesis. Diabetes 51: 2405-2411.

27. Zinker BA, Rondinone CM, Trevillyan JM, Gum RJ, Clampit JE, et al. (2002) PTP1B antisense oligonucleotide lowers PTP1B protein, normalizes blood glucose, and improves insulin sensitivity in diabetic mice. Proc Natl Acad Sci U S A 99: 11357-11362.

28. Eguchi J, Wang X, Yu S, Kershaw EE, Chiu PC, et al. (2011) Transcriptional control of adipose lipid handling by IRF4. Cell Metab 13: 249-259.

29. Scherer PE, Williams S, Fogliano M, Baldini G, Lodish HF (1995) A novel serum protein similar to $\mathrm{Clq}$, produced exclusively in adipocytes. J Biol Chem 270: 26746-26749.

30. Almind K, Kahn CR (2004) Genetic determinants of energy expenditure and insulin resistance in diet-induced obesity in mice. Diabetes 53: 3274-3285.

31. Loh K, Deng H, Fukushima A, Cai X, Boivin B, et al. (2009) Reactive oxygen species enhance insulin sensitivity. Cell Metab 10: 260-272.

32. Katsuki A, Sumida Y, Gabazza EC, Murashima S, Furuta M, et al. (2001) Homeostasis model assessment is a reliable indicator of insulin resistance during follow-up of patients with type 2 diabetes. Diabetes Care 24: 362-365.

33. Arya G, Niven D (2009) Production of haemolysins by strains of the actinobacillus minor. Vet Microbiol 141: 332-341.

34. Wang Y, Seidel J, Tsui BMW, Vaquero JJ, Pomper MG (2006) Performance evaluation of the GE healthcare eXplore VISTA dual-ring small-animal PET scanner. J Nucl Med 47: 1891-1900.

35. Moody A, Stan M, Stan M, Gliemann J (1974) A simple free fat cell bioassay for insulin. Horm Metab Res 6: 12-16.

36. Fine J, DiGirolamo M (1997) A simple method to predict cellular density in adipocyte metabolic incubations. Int J Obes 21: 764-768.

37. Wang MY, Lee Y, Unger RH (1999) Novel form of lipolysis induced by leptin. J Biol Chem 274: 17541-17544.

38. Bai Y, Zhang S, Kim KS, Lee JK, Kim KH (1996) Obese gene expression alters the ability of $30 \mathrm{~A} 5$ preadipocytes to respond to lipogenic hormones. J Biol Chem 271: 13939-13942.

39. Kersten S (2001) Mechanisms of nutritional and hormonal regulation of lipogenesis. EMBO Rep 2: 282-286.

40. Horton JD, Goldstein JL, Brown MS (2002) SREBPs: activators of the complete program of cholesterol and fatty acid synthesis in the liver. J Clin Invest 109: 1125-1131.

41. Waring JF, Ciurlionis R, Clampit JE, Morgan S, Gum RJ, et al. (2003) PTP1B antisense-treated mice show regulation of genes involved in lipogenesis in liver and fat. Mol Cell Endocrinol 203: 155-168.

42. Muthusamy VS, Anand S, Sangeetha KN, Sujatha S, Arun B, et al. (2008) Tannins present in cichorium intybus enhance glucose uptake and inhibit adipogenesis in 3T3-L1 adipocytes through PTP1B inhibition. Chem Biol Interact 174: 69-78.

43. Miranda S, González-Rodríguez A, Revuelta-Cervantes J, Rondinone CM, Valverde AM (2010) Beneficial effects of PTP1B deficiency on brown adipocyte differentiation and protection against apoptosis induced by pro- and antiinflammatory stimuli. Cell Signal 22: 645-659.

44. Matsuo K, Bettaieb A, Nagata N, Matsuo I, Keilhack H, et al. (2011) Regulation of brown fat adipogenesis by protein tyrosine phosphatase 1B. PLoS One 6: e16446.

45. Agouni A, Mody N, Owen C, Czopek A, Zimmer D, et al. (2011) Liver-specific deletion of protein tyrosine phosphatase (PTP) 1B improves obesity-and pharmacologically-induced endoplasmic reticulum stress. Biochem J 438: 369-378.

46. Shimizu S, Ugi S, Maegawa H, Egawa K, Nishio Y, et al. (2003) Proteintyrosine phosphatase $1 \mathrm{~B}$ as new activator for hepatic lipogenesis via sterol regulatory element-binding protein-1 gene expression. J Biol Chem 278: 43095-43101.

47. Bence KK (2010) Hepatic PTP1B deficiency: The promise of a treatment for metabolic syndrome? J Clin Metab Diabetes 1: 27-33.

48. Franckhauser S, Muñoz S, Pujol A, Casellas A, Riu E, et al. (2002) Increased fatty acid re-esterification by PEPCK overexpression in adipose tissue leads to obesity without insulin resistance. Diabetes 51: 624-630.

49. Halberg N, Khan T, Trujillo ME, Wernstedt-Asterholm I, Attie AD, et al. (2009) Hypoxia-inducible factor 1 \{alpha\} induces fibrosis and insulin resistance in white adipose tissue. Mol Cell Biol 29: 4467-4483. 
50. Suwaki N, Vanhecke E, Atkins KM, Graf M, Swabey K, et al. (2011) A HIFregulated VHL-PTP1B-src signaling axis identifies a therapeutic target in renal cell carcinoma. Sci Trans Med 3: 85ra47.

51. Hamilton BS, Paglia D, Kwan AYM, Deitel M (1995) Increased obese mRNA expression in omental fat cells from massively obese humans. Nat Med 1: 953-956.

52. Lönnqvist F, Nordfors L, Jansson M, Thörne A, Schalling M, et al. (1997) Leptin secretion from adipose tissue in women. Relationship to plasma levels and gene expression. J Clin Invest 99: 2398-2404
53. Kahn BB (1996) Glucose transport: pivotal step in insulin action. Diabetes 45 : 1644-1654.

54. Foley J, Laursen A, Sonne O, Gliemann J (1980) Insulin binding and hexose transport in rat adipocytes. Diabetologia 19: 234-241.

55. Pérez C, Fernández-Galaz C, Fernández-Agulló T, Arribas C, Andrés A, et al. (2004) Leptin impairs insulin signaling in rat adipocytes. Diabetes 53: 347-353.

56. Galic S, Hauser C, Kahn BB, Haj FG, Neel BG, et al. (2005) Coordinated regulation of insulin signaling by the protein tyrosine phosphatases PTP1B and TCPTP. Mol Cell Biol 25: 819-829. 